\title{
Myeloid-derived suppressor cells-new and exciting players in lung cancer
}

\author{
Zhenzhen Yang ${ }^{1 \dagger}$, Jiacheng Guo ${ }^{2,3 \dagger}$, Lanling Weng ${ }^{1}$, Wenxue Tang ${ }^{4,5^{*}}$, Shuiling $\operatorname{Jin}^{1 *}$ and Wang Ma ${ }^{1 *}$
}

\begin{abstract}
Lung cancer (LC) is the leading cause of cancer-related death worldwide due to its late diagnosis and poor outcomes. As has been found for other types of tumors, there is increasing evidence that myeloid-derived suppressor cells (MDSCs) play important roles in the promotion and progression of LC. Here, we briefly introduce the definition of MDSCs and their immunosuppressive functions. We next specifically discuss the multiple roles of MDSCs in the lung tumor microenvironment, including those in tumor growth and progression mediated by inhibiting antitumor immunity, and the associations of MDSCs with a poor prognosis and increased resistance to chemotherapy and immunotherapy. Finally, we also discuss preclinical and clinical treatment strategies targeting MDSCs, which may have the potential to enhance the efficacy of immunotherapy.
\end{abstract}

Keywords: Lung cancer, MDSCs, Immunosuppression, Anticancer

\section{Introduction}

Within the global cancer burden, lung cancer (LC) is the most commonly diagnosed cancer, accounting for $11.6 \%$ of all cancer cases, and the leading cause of cancer-related death, accounting for $18.4 \%$ of all cancer-related deaths [1]. Despite tremendous advances in LC treatment, the overall survival (OS) of LC patients remains poor. The tumor immune microenvironment (TIME) is dynamic during malignant progression, in which all cells in the TIME are involved, especially $\mathrm{T}$ lymphocytes; these cells are now considered to be key components of the autoanticancer response and have been shown to have therapeutic effects in a large proportion of cases by blocking "immune checkpoint" activation. However, despite the increasing success of these new therapies, a large number of patients have not benefited. Therefore, there is an urgent need to identify new elements of the host immune system that can serve as relevant biomarkers and therapeutic targets. Recent studies have increasingly emphasized the role of the

\footnotetext{
*Correspondence: doctormawang@126.com; fccjinsl@zzu.edu.cn; wenxue.tang@yahoo.com

${ }^{\dagger}$ Zhenzhen Yang and Jiacheng Guo contributed equally to this work. ${ }^{4}$ Departments of Otolaryngology, The Second Affiliated Hospital of Zhengzhou University, Zhengzhou 450000, Henan, China

${ }^{1}$ Department of Oncology, The First Affiliated Hospital of Zhengzhou

University, NO.1 Eastern Jianshe Road, Zhengzhou 450052, Henan, China

Full list of author information is available at the end of the article
}

TIME in the treatment of resistance. Immunosuppressive cells, such as bone marrow-derived suppressor cells (MDSCs), tumor-associated macrophages (TAMs), and regulatory $\mathrm{T}$ (Treg) cells, act as suppressive TIME components to attenuate immune responses [2]. Among these cells, MDSCs have roles in the prognosis, development, and treatment of LC that have been paid increasing attention $[3,4]$. MDSCs are a group of highly heterogeneous cells derived from immature myeloid progenitors that are usually divided into two subpopulations: polymorphonuclear MDSCs (PMN-MDSCs) and monocytic MDSCs (M-MDSCs) [5-7]. MDSCs, as revealed by current research, are involved not only in the control of antitumor immune responses but also in tumor progression by promoting tumor angiogenesis, tumor cell invasion, and premetastatic niche formation $[8,9]$. The levels of MDSCs are also closely related to clinical outcomes and therapeutic effects in LC patients [10]. In this review, we discuss the major subtypes and inhibitory functions of MDSCs in LC, as well as their clinical significance. In addition, we also emphasize that MDSC-targeted therapeutic procedures, administered either alone or in combination with chemotherapeutic and/or immunotherapeutic regimens, have potential therapeutic benefits in LC.

(c) The Author(s). 2020 Open Access This article is distributed under the terms of the Creative Commons Attribution 4.0 International License (http://creativecommons.org/licenses/by/4.0/), which permits unrestricted use, distribution, and reproduction in any medium, provided you give appropriate credit to the original author(s) and the source, provide a link to the Creative Commons license, and indicate if changes were made. The Creative Commons Public Domain Dedication waiver (http://creativecommons.org/publicdomain/zero/1.0/) applies to the data made available in this article, unless otherwise stated. 


\section{Main phenotypic and functional characteristics of MDSCs}

Early studies in mice have highlighted a shared, systemic expansion of myeloid cells bearing the markers CD11b and Gr1, but current research suggests that MDSCs can be divided into two large groups of cells termed PMN-MDSCs

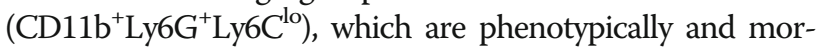
phologically similar to neutrophils, and M-MDSCs $\left(\mathrm{CD} 11 \mathrm{~b}^{+} \mathrm{Ly}_{6 \mathrm{G}^{-}} \mathrm{Ly}_{6 \mathrm{C}}{ }^{\mathrm{hi}}\right)$, which are similar to monocytes in terms of morphology and phenotype $[6,10,11]$. In humans, according to morphological and phenotypic features, the cells equivalent to PMN-MDSCs are mostly defined as

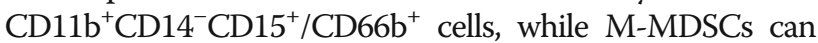
be defined as $\mathrm{CD} 11 \mathrm{~b}^{+} \mathrm{CD} 15^{-} \mathrm{CD} 14^{+} \mathrm{HLA}-\mathrm{DR}^{- \text {low }}$ cells [12]. In addition, M-MDSCs also express the myeloid marker CD33, and PMN-MDSCs display CD33 ${ }^{\text {dim }}$ staining [13]. However, Lin $^{-}$(including CD3, CD14, CD15, CD19, CD56)

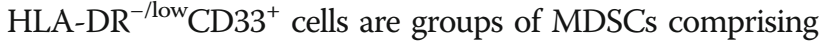
relatively immature progenitors. These immature cells are identified as eMDSCs [6]. However, there are still no uniform standards for surface molecular markers of human MDSCs, and many other markers are being reported gradually. From the perspective of $\mathrm{LC}$, according to multicolor immunofluorescence staining evaluated by fluorescenceactivated cell sorting (FACS), the following phenotypes of MDSCs have been reported (shown in Table 1):

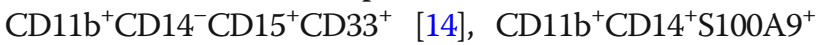
[15], CD16 ${ }^{\text {low }} \mathrm{CD} 11 \mathrm{~b}^{+} \mathrm{CD} 14^{-} \mathrm{HLA}^{-\mathrm{DR}}{ }^{-} \mathrm{CD} 15^{+} \mathrm{CD} 33^{+}$[16], $\mathrm{CD}^{+} 4^{+} \mathrm{HLA}^{-\mathrm{DR}^{-/ \text {low }}}[17,18], \mathrm{B} 7-\mathrm{H}^{+}{ }^{+} \mathrm{CD} 14^{+} \mathrm{HLA}^{-\mathrm{DR}^{- \text {llow }}}$

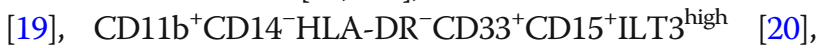
$\mathrm{Lin}^{-} \mathrm{CD} 14^{-} \mathrm{CD} 11 \mathrm{~b}^{+} \mathrm{CD} 39^{+} \mathrm{CD} 73^{+}[21], \mathrm{Lin}^{-} \mathrm{CD} 14^{+} \mathrm{CD} 11 \mathrm{~b}^{+} \mathrm{C}$ $\mathrm{D} 9^{+} \mathrm{CD} 73^{+}$[21], $\mathrm{Lin}^{-} \mathrm{CD} 14^{+} \mathrm{CD} 15^{+} \mathrm{H}$ LA-DR ${ }^{-}$[22], $\mathrm{Lin}^{-} \mathrm{C}$ D14 ${ }^{+}$CD15- HLA-DR ${ }^{-}$[22], Lin $^{-}$CD14 ${ }^{-}$HLA-DR ${ }^{-}$[22], Lin$\mathrm{CD}_{3}{ }^{+} \mathrm{CD} 14^{+} \mathrm{CD} 15^{-}$HLA-DR ${ }^{-}[25], \mathrm{CD}^{-} 3^{+} \mathrm{CD} 11 \mathrm{~b}^{+} \mathrm{CD} 14$ ${ }^{-}$[27], CD $33^{+} \mathrm{CD} 11 \mathrm{~b}^{+} \mathrm{CD} 14^{+} \mathrm{HLA}^{-\mathrm{DR}}{ }^{- \text {low }}$ [27], and CCR $5^{+} \mathrm{HLA}^{-\mathrm{DR}} \mathrm{R}^{- \text {low }} \mathrm{CD} 11 \mathrm{~b}^{+} \mathrm{CD} 14^{+} \mathrm{CD} 15^{-}[28]$.

The criteria for characterizing the phenotype of MDSCs by flow cytometry are relatively defined, and immunosuppressive function is a functional standard defined for MDSCs. While MDSCs were initially described as merely T cell suppressive, emerging evidence suggests that MDSCs also interact with and modulate the function of other immune cells, particularly macrophages (Mø) $[29,30]$, NK cells [31, 32], Treg cells [33], and B cells [34]. Moreover, MDSCs, TAMs, and dendritic cells (DCs) have been reported to interact and cross-promote their immunosuppressive activities in the tumor microenvironment [35]. Most of the available data indicate that MDSCs have different functional characteristics between the peripheral lymphoid organs and tumor tissues [36]. In most reports, the proportion of PMN-MDSCs in the peripheral lymphoid organs is much higher than that of M-MDSCs. Moreover, PMN-MDSCs have relatively moderate suppressive activity and play a major role in the regulation of tumor-specific immune responses, ultimately leading to the development of tumor-specific T cell tolerance. In tumor tissue, MDSCs have relatively strong suppressive functions, and M-MDSCs account for a greater proportion and more suppression than PMN-MDSCs and can rapidly differentiate into TAMs and DCs [37]. These findings suggest that targeting only one branch of myeloid cells (monocytes and/or Mø or granulocytes) or only intratumoral populations will not be sufficient for achieving therapeutic benefits. They may also indicate that the differences in the mechanisms regulating MDSC function in tumors and the peripheral lymphoid organs affect targeted therapies directed at these cells.

\section{Mechanisms underlying MDSC-mediated immunosuppression in LC}

MDSCs are the major suppressor population of the immune system, with the ability to inhibit adaptive and innate immune responses. The immunosuppressive mechanisms of MDSCs have been elucidated, especially in cancer growth, since MDSCs play a key role in tumor evasion of immune surveillance (Fig. 1).

\section{Metabolic mechanisms}

Metabolic reprogramming is a core requirement for tumor cells to meet the energy needs of rapid cell proliferation and to adapt to the tumor microenvironment. This event leads to altered cellular signaling, enzymatic activity, and/or metabolic flux during disease, such as the initiation of aerobic glycolysis (Warburg effect) and changes in oxidative phosphorylation, which can penetrate the tumor microenvironment and affect immune cells [38].

MDSCs that inhibit $\mathrm{T}$ cell function mainly depend on the following three metabolic modes: (1) Arginase (Arg)1 consuming arginine, (2) inducible nitric oxide synthase (iNOS) producing nitric oxide (NO), and (3) processes producing reactive oxygen species (ROS), including the superoxide anion (O2-), hydrogen peroxide (H2O2), and peroxynitrite (PNT) (ONOO-). The inhibitory activity of Arg-1 is based on its role in the hepatic urea cycle, which metabolizes L-arginine into L-ornithine. Increased accumulation of Arg-1 results in L-arginine depletion from the microenvironment, an event that inhibits $\mathrm{T}$ cell proliferation by reducing $\mathrm{T}$ cell $\mathrm{CD} 3 \delta$ expression $[14,39]$ or by preventing $\mathrm{T}$ cells from upregulating the cell expression of the cycle regulators cyclin D3 and Cyclin-dependent kinase 4 (CDK4), thereby arresting the cell cycle in the G0/G1 phase [40]. A pegylated form of the catabolic enzyme Arg I (peg-Arg I) can enhance the growth of tumors in mice in a manner that correlates with increased MDSC numbers through general control of the nonrepressed-2 eIF2 $\alpha$ kinase [41]. $\mathrm{NO}$ can react with superoxide to form PNT and then directly inhibit $\mathrm{T}$ cells by nitrifying TCR, thereby reducing the affinity of TCR for antigen-MHC complexes 
Table 1 Clinical significance of MDSCs in lung cancer

\begin{tabular}{|c|c|c|c|c|c|}
\hline Refs. & Phenotype (MDSCs) & $\begin{array}{l}\text { Tumor tissue } \\
(\mathrm{TT}) / \\
\text { peripheral } \\
\text { blood (PB) }\end{array}$ & NSCLC/SCLC & $\begin{array}{l}\text { No. of } \\
\text { patients }\end{array}$ & Implications \\
\hline$[14]$ & $\mathrm{CD}_{11 \mathrm{~b}^{+} \mathrm{CD} 14^{-} \mathrm{CD} 15^{+} \mathrm{CD} 33^{+}}$ & PB & $\begin{array}{l}\text { Advanced } \\
\text { NSCLC }\end{array}$ & 41 & $\begin{array}{l}\text { Decreased in the advanced-stage patients } \\
\text { who had clinical benefit (PR or SD) and in } \\
\text { the early-stage patients after removal of tumor. }\end{array}$ \\
\hline$[15]$ & $\mathrm{CD} 11 \mathrm{~b}^{+} \mathrm{CD} 14^{+} \mathrm{S} 100 \mathrm{Ag}^{+}$ & PB & $\begin{array}{l}\text { Advanced } \\
\text { NSCLC }\end{array}$ & 24 & Poor chemotherapy response and short PFS \\
\hline$[16]$ & $\mathrm{CD} 16^{\text {low }} \mathrm{CD} 11 \mathrm{~b}^{+} \mathrm{CD} 14^{-} \mathrm{HLA}-\mathrm{DR} \mathrm{R}^{-} \mathrm{CD} 15^{+} \mathrm{CD} 33^{+}$ & PB & $\begin{array}{l}\text { Advanced } \\
\text { NSCLC }\end{array}$ & 185 & $\begin{array}{l}\text { Significantly increased compared to healthy } \\
\text { controls }\end{array}$ \\
\hline$[17]$ & CD $14^{+} H L A-D R^{-/ l o w ~}$ & PB & NSCLC & 60 & Negatively correlated with PFS \\
\hline$[18]$ & $\mathrm{CD}_{14}^{+} \mathrm{HLA}-\mathrm{DR}{ }^{-/ \text {low }}$ & $\mathrm{PB}$ & SCLC & 42 & Independent biomarker for poor prognosis \\
\hline$[19]$ & $\mathrm{B} 7-\mathrm{H}^{+} \mathrm{CD} 14^{+} \mathrm{HLA}-\mathrm{DR} \mathrm{R}^{-/ \mathrm{low}}$ & PB & NSCLC & 111 & Decreased RFS \\
\hline$[20]$ & $\mathrm{CD} 11 \mathrm{~b}^{+} \mathrm{CD} 14^{-} \mathrm{HLA}-\mathrm{DR} \mathrm{R}^{-} \mathrm{CD} 33^{+} \mathrm{CD} 15^{+} \| \mathrm{LT} 3^{\text {high }}$ & $\mathrm{PB}$ & $\begin{array}{l}\text { Stage IV } \\
\text { NSCLC }\end{array}$ & 105 & Decreased OS \\
\hline$[21]$ & $\begin{array}{l}\operatorname{lin}^{-} \mathrm{CD} 14^{-} \mathrm{CD} 11 \mathrm{~b}^{+} \mathrm{CD} 39^{+} / \mathrm{CD} 73^{+} \text {PMN-MDSCs } \\
\operatorname{lin}^{-} \mathrm{CD} 14^{+} \mathrm{CD} 11 \mathrm{~b}^{+} \mathrm{CD} 39^{+} / \mathrm{CD}_{3} 3^{+} \mathrm{M}-\mathrm{MDSCs}\end{array}$ & PB & NSCLC & 24 & $\begin{array}{l}\text { Decreased with chemotherapy cycles in SD } \\
\text { and PR groups, increased in PD group. }\end{array}$ \\
\hline$[22]$ & $\mathrm{Lin}^{-} \mathrm{CD} 14^{+} \mathrm{CD}_{15}{ }^{+} \mathrm{CD} 11 \mathrm{~b}^{+} \mathrm{CD} 33^{+} \mathrm{HLA}-\mathrm{DR}^{-}$ & PB & NSCLC & 110 & $\begin{array}{l}\text { Independent prognostic marker for decreased } \\
\text { PFS and OS. }\end{array}$ \\
\hline$[23]$ & $\operatorname{Lin}^{-} \mathrm{CD} 14^{-} \mathrm{HLA}-\mathrm{DR}{ }^{-}$ & PB & NSCLC & 46 & $\begin{array}{l}\text { After three cycles, bevacizumab-based } \\
\text { chemotherapy significantly reduced the level } \\
\text { of } \text { Lin }^{-} C D 14^{-} H L A-D R^{-} \text {cells. }\end{array}$ \\
\hline$[24]$ & Lox-1+ PMN-MDSCs & PB & NSCLC & 34 & $\begin{array}{l}\text { Patients with a higher ratio of Tregs to } \\
\text { Lox-1 } 1^{+} \text {PMN-MDSCs in the blood after the 1st } \\
\text { nivolumab had better PFS. }\end{array}$ \\
\hline$[25]$ & $\mathrm{Lin}^{-} \mathrm{CD} 33^{+} \mathrm{CD}_{14}^{+} \mathrm{CD}_{15}^{-} \mathrm{HLA}^{-\mathrm{DR}}{ }^{-}$ & PB & $\begin{array}{l}\text { Metastatic } \\
\text { NSCLC }\end{array}$ & 61 & Decreased OS in anti-PD-1 treatment. \\
\hline$[26]$ & 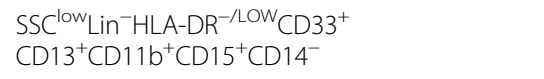 & $\mathrm{PB}$ & $\begin{array}{l}\text { stage IIIB or } \\
\text { IV NSCLC }\end{array}$ & 53 & $\begin{array}{l}\text { PMN-MDSCs ( } \geq 6 \text { cell/ } / \mu \text { l) showed a significantly } \\
\text { improved survival in anti-PD- } 1 \text { treatment. }\end{array}$ \\
\hline$[27]$ & 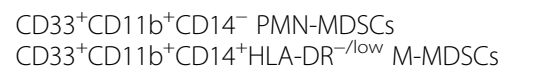 & PB & NSCLC & 7 & Both subtypes decreased after SBRT treatment. \\
\hline [28] & $\begin{array}{l}\text { CD } 11 b^{+} H L A-D R^{-/ l o w} C D 14^{-} C D 15^{+} \text {PMN-MDSCs } \\
\text { CCR5 }{ }^{+} H L A-D R^{-1 l o w} C D 11 b^{+} C D 14^{+} C D 15^{-} M- \\
\text { MDSCs }\end{array}$ & $\pi$ and $P B$ & $\begin{array}{l}\text { Resectable } \\
\text { NSCLC }\end{array}$ & 42 & $\begin{array}{l}\text { TT PMN-MDSCs displayed higher PD-L1 expression } \\
\text { levels than the same cells in the PB. } \\
\text { Significant correlations between lower total } \\
\text { PMN-MDSCs and CCR5 }{ }^{+} \text {M-MDSCs frequencies in } \\
\text { the peripheral blood } \\
\text { and improved RFS. }\end{array}$ \\
\hline
\end{tabular}

$P R$ partial response, SD stable disease, $P D$ progressive disease, $P F S$ progress free survival, $R F S$ recurrence-free survival, $O S$ overall survival, $S B R T$ stereotactic body radiotherapy

presented by cancer cells and blocking the migration of $\mathrm{T}$ cells by nitrating $\mathrm{T}$ cell-specific chemokines [42, 43]. The two major subpopulations of MDSCs exploit different mechanisms to inhibit $\mathrm{T}$ cell proliferation. PMNMDSCs express high levels of ROS and low levels of NO, whereas M-MDSCs are the opposite, and both subpopulations express arginase. Given that ROS are unstable and active only for a short period of time, PMN-MDSCs require tight cell-cell contact to act on $\mathrm{T}$ cells. This contact is provided by antigen-specific interactions with $\mathrm{T}$ cells [44]. M-MDSCs produce large amounts of NO, Arg1, and immunosuppressive cytokines. These molecules have a much longer half-life than ROS and require cell access, but no close contact is required between M-MDSCs and T cells. Therefore, M-
MDSCs are mainly effective in inhibiting nonspecific $\mathrm{T}$ cell responses [7, 36].

In a preclinical model of pancreatic cancer, silencing lactate dehydrogenase isoform A decreased the frequency of MDSCs in the mouse spleen and resulted in improved cytolytic function of NK cells. Accordingly, lactate, which induces hypoxia-inducible factor- $1 \alpha$ (HIF- $1 \alpha)$, acts as an endogenous inhibitor of histone deacetylases (HDACs), regulating the transcription of genes involved in metabolism and immunity [45] and thereby increasing the frequency of MDSCs generated from mouse bone marrow cells in vitro [46]. The increase in CD45 tyrosine phosphatase activity in the hypoxic environment of the tumor promotes the downregulation of STAT3 expression, thereby promoting the differentiation of M-MDSCs into TAMs [30]. 


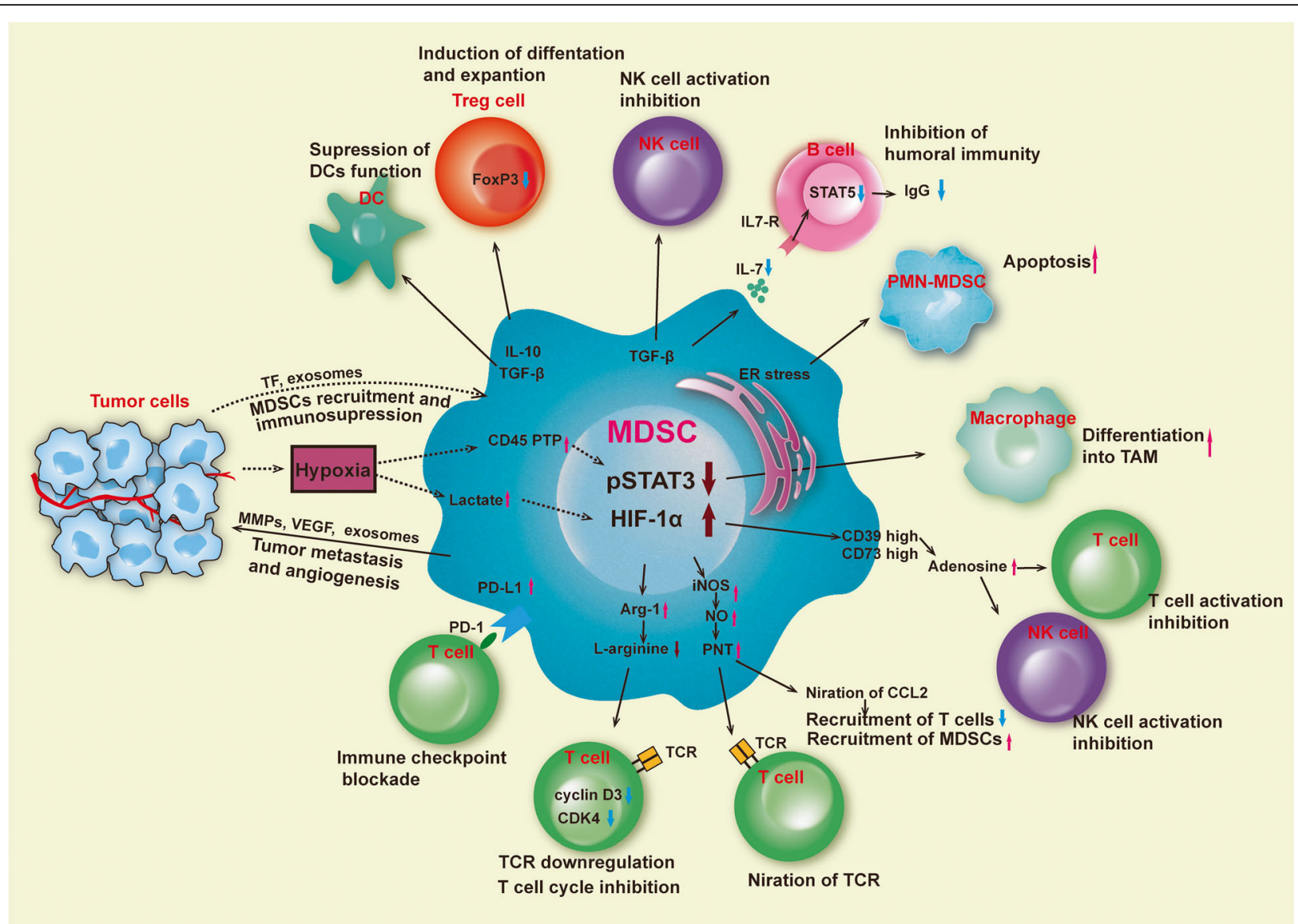

Fig. $1 \mathrm{Imm}$ unosuppressive functions of MDSCs in the tumor microenvironment. DCs: dendritic cells; TAM: tumor-associated macrophage; ER: endoplasmic reticulum; Arg-1: arginase 1; iNOS: inducible nitric oxide synthase; HIF-1a: hypoxia-inducible factor-1a; STAT3: signal transducer and activator of transcription 3; VEGF: vascular endothelial growth factor; TF: tissue factor. In the tumor microenvironment, MDSCs are exposed to hypoxic conditions. This leads to an increase in HIF-1a-mediated elevation of Arg1 and iNOS and upregulation of inhibitory PD-L1 on the MDSC surface, all of which can suppress T cell immune activity. It also produces IL-10 and TGF- $\beta$, etc., which attract Treg cells to the tumor site and enhance their immunosuppressive functions, while suppressing the functions of B cells, NK cells, and DCs. Adenosine from CD39-high/CD73-high MDSCs is a further major NK suppressive factor. Much of the STAT3 activity in MDSCs is greatly reduced due to the effects of hypoxia. This leads to the rapid differentiation of M-MDSCS to TAMs. PMN-MDSCs die quickly due to ER stress. Factors released by dying cells can promote immunosuppressive mechanisms. At the same time, MDSCs can promote tumor angiogenesis and metastasis by producing VEGF, MMPs, and exosomes. Tumor tissue-derived exosomes can also affect MDSC recruitment and immunosuppression

The ATP: AMP ratio of cells, as an integral part of overall metabolism, is monitored by mTOR. mTOR-mediated HIF- $1 \alpha$ induction plays an important role in activating glycolysis [47]. Ectonucleotidases are localized on tumor cells and different populations of immune cells that hydrolyze ATP or ADP into AMP via CD39 (ectonucleoside triphosphate diphosphohydrolase-1) and further process AMP into adenosine via CD73 (ecto- $5^{\prime}$-nucleotidase) in the tumor microenvironment $[48,49]$. Li et al. recognized that TGF- $\beta$-induced HIF- $1 \alpha$ activation was mTOR dependent in MDSCs in non-small cell lung cancer (NSCLC) patients and was critical for CD39/CD73 induction under normoxic conditions. Metformin inhibited the expression and activity of CD39/CD73 through activation of AMPK $\alpha$ and inhibition of the HIF- $1 \alpha$ pathway to impair MDSC immunosuppressive activity, thereby improving antitumor $\mathrm{T}$ cell responses [50].

\section{STAT signaling pathway}

One of the major factors that drives MDSC expansion in cancer is transcriptional factor signal transducer and activator of transcription 3 (STAT3). The activation of STAT3 can inhibit apoptosis in myeloid cells and prevent these cells from differentiating into mature cells by promoting the expression of the antiapoptotic genes Bcl$\mathrm{xL}, \mathrm{c}-\mathrm{myc}$, and cyclin D1 [51]. Spontaneous bronchoalveolar adenocarcinoma in CCSP-rtTA/(tetO)7-Stat3C bitransgenic mice is directly induced by the overexpression of constitutively active Stat3C in alveolar type II (AT II) epithelial cells and continued activation of the 
Stat3 signaling pathway [52]. Wu et al. showed that the overexpression of Stat3C in ATII epithelial cells induced the accumulation of MDSCs in the lungs and blood of transgenic mice and that phosphorylation of the protooncogenic intracellular signaling molecules Stat3, Erk1/ 2, and P38 was significantly increased in MDSCs, accompanied by decreases in the frequencies of $\mathrm{CD} 4^{+}$and $\mathrm{CD}^{+} \mathrm{T}$ cells. In the bronchioalveolar lavage fluid and plasma of doxycycline-treated transgenic mice, the concentrations of the MDSC-associated cytokines IL-1 $\beta$, IL-6, IL-10, IL-13, INF- $\gamma$, TNF- $\alpha$, and GM-CSF were significantly increased, which stimulated alveolar monocytes/ macrophages to undergo MDSC conversion in vitro [53]. However, a recent study showed that STAT3 had a new role in the differentiation of MDSCs independent of HIF$1 \alpha$. The authors reported profound downregulation of STAT3 activity in MDSCs in tumors compared to the same cells in the peripheral lymphoid organs and blood. This reduction was a key factor in regulating the differentiation of MDSCs into TAMs. Hypoxia caused an increase in CD45 tyrosine phosphatase activity in M-MDSCs, which resulted in a selective decrease in STAT3 activity in M-MDSCs in tumors. Upregulation of CD45 phosphatase activity was mediated by a disruption in CD 45 protein dimerization caused by increased CD45 sialylation [30].

Wang et al. revealed that $\mathrm{B}$ cell differentiation and function were impaired during tumor progression in mouse models of LC. Most of the impairments were attributable to the direct effects of MDSCs, and they were related to and seemingly mediated by a IL-7-mediated reduction in STAT5 signaling and dysfunctional B cell responses. In addition, the authors revealed that TGF- $\beta$ (an MDSC-associated cytokine) was a central inhibitor of IL-7 signaling in B cells in the TIME [34].

\section{Exosomes}

A growing number of studies have demonstrated that MDSC-released exosomes have a role in immunosuppression $[54,55]$. Deng et al. found that although doxorubicin treatment was largely efficacious in inhibiting primary tumors, it significantly increased the incidence and burden of pulmonary metastasis through miR-126a ${ }^{+}$MDSCderived exosomes. Induction of miR-126a ${ }^{+}$MDSC-derived exosomes by doxorubicin strongly increased the expression of the inflammatory cytokine IL-13. These proinflammatory changes promoted the outgrowth of both MDSCs and Th2 cells in the lungs, where these cells increased angiogenesis and promoted the lung metastasis of breast cancer via miR-126a ${ }^{+}$MDSC-derived exosomes [56]. Interestingly, exosomes from tumor cells also contribute to the function of MDSCs. A study found that the expression of PD-L1 in MDSCs could be increased after tumorderived exosomes were transferred from tumor cells to MDSCs in glioma and LC tumor models. This expression was related to the increased expression of Arg1 in MDSCs, the production of TGF- $\beta$, and the strengthened immunosuppressive activity of these cells [57].

\section{Caspase recruitment domain-containing protein 9}

Caspase recruitment domain-containing protein 9 (CARD9) is mainly expressed in myeloid cells $[58,59]$ and is an important adaptor protein in innate immunity, as it regulates innate immunity and affects adaptive immune responses [60,61]. Qu et al. demonstrated the role of CARD9 in the development of LC for the first time. They found that CARD9 prevented LC development by suppressing the expansion of MDSCs and production of indoleamine 2,3-dioxygenase (IDO). Further studies suggested that knocking down CARD9 expression enhanced the expression of IDO in MDSCs through the noncanonical NF$\mathrm{KB}$ pathway, which manifested as increased expression of NIK, p-P100, p52, and RelB. Thus, the CARD9-NF-kBIDO pathway in MDSCs can inhibit the suppressive function of MDSCs and prevent LC development [62].

\section{Long noncoding RNAs}

Long noncoding (Lnc) RNAs are highly important factors associated with tumors and may be used as markers for tumor diagnosis, which is valuable for targeted therapy.

The lncRNA HOXA transcript antisense RNA myeloidspecific 1 (HOTAIRM1), which is transcribed by RNA polymerase II, is located between the human HOXA1 and HOXA2 genes. HOTAIRM1/HOXA1 has been shown to modulate myeloid cell differentiation [63]. Knocking down HOTAIRM1 expression significantly inhibits the expression of HOXA1 and HOXA4 and reduces the induction of myeloid differentiation gene transcripts, such as CD11b and CD18, during all-trans retinoic acid (ATRA)-induced granulocytic differentiation [64]. In the tumor tissue of LC patients, Tian et al. found that HOTAIRM1 was expressed

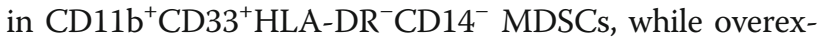
pression of HOTAIRM1 downregulated the expression of Arg-1 and ROS in MDSCs. In different LC subtypes, HOTAIRM1 was mainly expressed in MDSCs in lung adenocarcinoma. The specific mechanism may be that HOTAIRM1 can enhance the expression of HOXA1 in MDSCs and high levels of HOXA1 can delay tumor progression and enhance the antitumor immune response by downregulating the immunosuppression mediated by MDSCs [65]. The lncRNA metastasis-associated lung adenocarcinoma transcript 1 (MALAT1), also known as nuclear enrichment autosomal transcript 2 (NEAT2), is widely expressed in mammals $[66,67]$. Abnormal expression of MALAT1 is observed in a variety of tumor tissues and is associated with a number of important biological processes, including proliferation, apoptosis, invasion, and metastasis $[68,69]$. Zhou et al. showed that the relative expression of the IncRNA MALAT1 in peripheral blood 
mononuclear cells (PBMCs) from LC patients was significantly lower than that in PBMCs from healthy controls. The relative expression of MALAT1 was moderately negatively correlated with the proportion of $\mathrm{CD}_{3} 3^{+} \mathrm{CD} 11 \mathrm{~b}^{+} \mathrm{HLA}$ $\mathrm{DR}^{-}$MDSCs. In vitro results indicated that knocking down MALAT1 expression significantly increased the proportion of MDSCs [70]. Almost simultaneously, their team discovered another lncRNA regulated by MDSCs. They showed that the IncRNA RUNXOR exhibited upregulated expression in MDSCs isolated from the peripheral blood of LC patients and that the expression of RUNX1, a target gene of RUNXOR, was downregulated. Furthermore, the expression of RUNXOR was higher in MDSCs isolated from tumor tissues than in cells from adjacent tissues. After RUNXOR knockdown, the expression of Arg1 in MDSCs was downregulated, and RUNX1 expression was restored. These results indicated that RUNXOR might affect the function of MDSCs by regulating RUNX1 [71]. Zheng et al. first reported that HIF-1 $\alpha$ upregulated the expression of the lncRNA Pvt1 in PMNMDSCs under hypoxic conditions. Pvt1 played a key role in regulating the immunosuppressive capacity of PMNMDSCs. Pvt1 knockdown reduced the levels of Arg1 and ROS in PMN-MDSCs and restored antitumor T cell responses. Therefore, the concept of targeting Pvt1 to attenuate PMN-MDSC-mediated immunosuppression may be a potential therapeutic strategy [72].

\section{MicroRNA}

MicroRNA (miRNA) networks regulate the differentiation, expansion, and suppression function of MDSC in the tumor microenvironment through different signaling pathways [73]. Research by Li et al. revealed that in LLC tumor models, miR-155 and miR-21 can promote the proliferation and immunosuppressive function of MDSCs via targeting SHIP-1 and phosphatase and tensin homolog, respectively, leading to STAT3 activation [74]. Subsequently, Wang et al. reported that miR-155 deficiency promotes solid tumor growth through increasing the recruitment of MDSCs to the tumor microenvironment and enhancing the tumor-promoting functions of the recruited MDSCs [75]. In addition, miR-9 regulates MDSC differentiation by targeting runt-related transcription factor 1 , an essential transcription factor in the regulation of MDSC differentiation and function [76].

\section{Tissue factor}

Exogenous coagulation, tissue factor (TF), and its noncoagulant isoforms have been found to promote both tumor progression and poor clinical outcomes [77, 78]. In a xenograft model, TF knockdown in A549 cells resulted in a significant decrease in fibrin deposition, with smaller concomitant reductions in $\mathrm{C} 3 \mathrm{~b} / \mathrm{iC} 3 \mathrm{~b} / \mathrm{C} 3 \mathrm{c}$ and $\mathrm{C} 5 \mathrm{~b}-9$ deposition, which represented complement activation, with relatively few MDSCs infiltrates and inhibited tumor growth [79]. These findings suggest that in the tumor microenvironment, TF-induced coagulation activates the complement system and subsequently recruits MDSCs to promote tumor growth.

\section{Endoplasmic reticulum stress}

The endoplasmic reticulum (ER) stress response is an evolutionarily conserved mechanism for protecting cells from various stress conditions, including hypoxia, nutrient deficiencies, and low $\mathrm{pH}$. In the tumor microenvironment, ER stress is associated with the fate of MDSCs. Condamine and colleagues found that in tumor-bearing mouse models of lung cancer, thymoma, colon cancer, and breast cancer, PMN-MDSCs induced more apoptosis than neutrophils or monocytes. Further studies have shown that this effect is mediated by changes in TNF-related apoptosis-induced ligand receptor (TRAIL$\mathrm{R})$ expression induced by ER stress in MDSCs. The short survival of MDSCs stimulates the proliferation of their precursors and further triggers their expansion [80].

In addition to mediating immunosuppressive mechanisms, MDSCs also affect the remodeling of the tumor microenvironment and tumor angiogenesis by producing VEGF and MMP9 [56], thereby promoting tumor progression. Interestingly, it has been reported that MDSCs can regulate the biology of cancer stem cells by affecting the IL-6/STAT3 and NO/NOTCH signaling pathways [81]. MDSCs endow stem-like qualities to multiple myeloma cells by inducing piRNA-823 expression and DNMT3B activation [82]. However, there is currently no published study on whether MDSCs affect the stemness of LC cells.

\section{Significance of MDSCs in LC}

As previously stated, various factors affecting MDSC expansion have been studied in multiple types of cancers and across various biological models. Like many other cancers, LC has high levels of MDSCs that are associated with resistance to chemotherapy, targeted therapy, and immunotherapy and can predict a poor prognosis [14-17, 70] (Table 1).

\section{Role of MDSCs in the development of LC}

A study of 185 Caucasian patients with NSCLC found that the frequency of $\mathrm{CD} 16^{\text {low }} \mathrm{CD} 11 \mathrm{~b}^{+} \mathrm{CD} 14^{-} \mathrm{HLA}$ $\mathrm{DR}^{-} \mathrm{CD} 15^{+} \mathrm{CD} 33^{+}$PMN-MDSCs was significantly increased in the NSCLC patients compared with healthy controls [16]. Liu et al. identified MDSCs with a

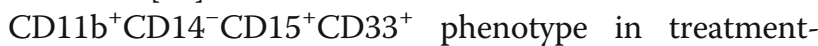
naive advanced NSCLC patients. These cells expressed IL-4R, IFN- $\gamma \mathrm{R}$, Arg- 1 , and iNOS and inhibited CD3 $\zeta$ expression in $\mathrm{CD}^{+} \mathrm{T}$ lymphocytes. In addition, $\mathrm{CD}_{11} \mathrm{~b}^{+} \mathrm{CD} 14^{-} \mathrm{MDSC}$ numbers were reduced in the patients who were responsive to treatment [14]. Feng and colleagues described the characteristics of

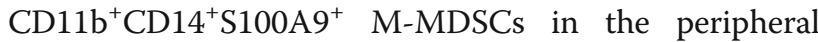


blood and their clinical relevance in patients with advanced NSCLC. High levels of CD11 ${ }^{+} \mathrm{CD} 14^{+}$S100A9 ${ }^{+}$ M-MDSCs were associated with a poor response to cisplatin-based chemotherapy and predicted shortened progression-free survival (PFS) [15].

Huang et al. observed for the first time that both the absolute number and percentage of CD14 ${ }^{+} \mathrm{HLA}_{-}-\mathrm{DR}^{- \text {llow }}$ cells were increased in NSCLC patients with metastasis. Furthermore, both the percentage and absolute number of $\mathrm{CD} 14^{+} \mathrm{HLA}-\mathrm{DR}{ }^{-/ \text {low }}$ cells prior to therapy negatively correlated with the clinical response and PFS following cisplatin-based chemotherapy in advanced NSCLC patients, suggesting that increased levels of immunosuppressive $\mathrm{CD} 14^{+} \mathrm{HLA}-\mathrm{DR}^{-/ \text {low }}$ cells might be associated with the poor prognosis of NSCLC. These suppressive cells upregulated the expression of gp91 ${ }^{\text {phox }}$, an important component of the ROS-generating enzyme NADPH oxidase [17]. Subsequently, for small cell lung cancer (SCLC) patients, the frequency of CD14 HLA-DR ${ }^{-/ \text {low }}$ MDSCs was also found to be negatively correlated with clinical outcomes [18]. Zhang et al. identified a new subset of MDSCs in the tumor microenvironment of NSCLC, B7-H3 ${ }^{+} \mathrm{CD} 14^{+} \mathrm{HLA}_{-} \mathrm{DR}^{-/ \text {low }}$ MDSCs (B7-H3 ${ }^{+}$ MDSCs). Their results suggested that the elevated frequency of this novel MDSC subpopulation correlated with a poor TNM stage and tumor metastasis and might be a predictor of poor recurrence-free survival (RFS) in patients with NSCLC. Further studies indicated that $\mathrm{B} 7-\mathrm{H3}^{+}$ MDSCs promoted cancer progression by producing IL-10 to induce Treg cells in the tumor microenvironment [19].

Scrimini et al. observed that the circulating levels of MDSCs (Lin ${ }^{-} \mathrm{HLA}-\mathrm{DR}^{-} \mathrm{CD} 33^{+} \mathrm{CD} 11 \mathrm{~b}^{+}$) and the serum concentration of Arg-1 were increased, and the surface expression of TCR $\zeta$ in circulating lymphocytes was reduced to a similar extent among patients with LC, chronic obstructive pulmonary disease (COPD), or both diseases. These results suggested that tumor immunosurveillance might be impaired in COPD patients, which may contribute to the increased risk of LC reported in these patients [83].

Immunoglobulin-like transcript 3 (ILT3) is a receptorcontaining immunoreceptor tyrosine-based inhibition motifs (ITIMs) that can be expressed on antigenpresenting cells and is an important regulator of DC tolerance $[84,85]$. ILT3 exists in membrane-bound and soluble forms and can interact with a yet unidentified ligand on $\mathrm{T}$ cells to induce $\mathrm{T}$ cell anergy, Treg cells, or T suppressor cells $[86,87]$. ILT3 is also expressed on MDSCs, and the ILT3 $3^{\text {high }}$ fraction of PMN-MDSCs $\left(\mathrm{CD} 11 \mathrm{~b}^{+} \mathrm{CD} 14^{-} \mathrm{HLA}^{-\mathrm{DR}}{ }^{-} \mathrm{CD} 33^{+} \mathrm{CD} 15^{+}\right)$correlates with a relatively poor outcome in stage IV NSCLC patients [20]. Nonetheless, it is debatable whether ILT3 alone determines the immunosuppressive status of MDSCs.

Vetsika et al. used flow cytometry to study the percentages and correlations of MDSCs and different immune cells in the peripheral blood of 110 chemotherapy-naive NSCLC patients and healthy controls. They identified two new monocytic subpopulations $\left(\mathrm{Lin}^{-} \mathrm{CD} 14^{+} \mathrm{CD} 15^{+} \mathrm{HLA}-\right.$ $\mathrm{DR}^{-}$and $\mathrm{Lin}^{-} \mathrm{CD} 14^{+} \mathrm{CD} 15^{-} \mathrm{HLA}^{\left.-\mathrm{DR}^{-}\right)}$and one granulocytic subpopulation ( $\mathrm{Lin}^{-} \mathrm{CD} 14^{-} \mathrm{HLA}-\mathrm{DR}^{-}$) based on the expression of the markers CD15 and CD14 in the immature myeloid cell population $\left(\mathrm{Lin}^{-} \mathrm{CD} 33^{+} \mathrm{CD} 11 \mathrm{~b}^{+} \mathrm{HLA}\right.$ $\mathrm{DR}^{-}$) in the peripheral blood. In this study, normal levels of Lin $^{-}$CD $14^{+}$CD15 ${ }^{+}$HLA-DR ${ }^{-}$M-MDSCs but not $\mathrm{Lin}^{-} \mathrm{CD} 14^{+} \mathrm{CD} 15^{-} \mathrm{HLA}^{-D R^{-}}$M-MDSCs at baseline were associated with improved patient PFS and OS by dramatically reducing the percentages of DCs and T helper cells via regulation of the expression of iNOS and ROS, respectively [22]. However, bevacizumab-based chemotherapy significantly reduces the levels of Lin $^{-}$CD14 ${ }^{-}$HLA-DR ${ }^{-}$PMN-MDSCs [23].

Most studies focus only on the proportion of MDSCs in the peripheral blood of patients with LC. Yamauchi et al. also focused on changes in MDSCs in the tumor tissues of patients with resectable NSCLC [28]. A significant increase in the frequency of circulating M-MDSCs was observed in the NSCLC patients compared with healthy donors (HDs). Moreover, the frequencies of $\mathrm{M}$ MDSCs and PMN-MDSCs were higher in the tumor tissue than in the peripheral blood of the same patients. This accumulation was associated with elevated concentrations of inflammatory mediators (CCL2, CCL3, CCL4, CCL5, IL-8, and CXCL10) involved in MDSC migration to and activation in the tumor microenvironment. An analysis of the MDSC immunosuppressive pattern showed increased programmed death-ligand 1 (PD-L1) expression on circulating cells from the patients compared with those from the HDs. Tumor PMN-MDSCs displayed higher PD-L1 expression levels than the same cell type in the peripheral blood. The frequency of CCR5 expression on circulating M-MDSCs was significantly higher in the patients than in the HDs. Clinical data analysis revealed negative correlations between RFS and the frequencies of PMN-MDSCs and CCR5 ${ }^{+}$M-MDSCs in the circulation but not in the tumors. Their findings suggest that the level of MDSCs in the peripheral blood but not in tumor tissue predicts recurrence following surgery [28].

\section{MDSCs are associated with chemotherapy resistance}

As previously described, the ectonucleotidases CD39 and CD73 hydrolyze ATP or ADP into AMP and further yield adenosine in a highly coordinated enzymatic process $[88,89]$. CD39 and CD73 are expressed by cancer cells and different immune cell populations and are responsible for the regulation of the balance between proinflammatory ATP and immunosuppressive adenosine in the tumor microenvironment [48, 49, 90, 91]. Li et al. demonstrated that CD39 and CD73 were expressed on MDSCs in the peripheral blood of patients with NSCLC and that CD $39^{+} \mathrm{CD} 73^{+}$MDSCs had an immunosuppressive function. Further analysis revealed that the 
percentage of $\mathrm{CD}_{3} 9^{+} \mathrm{CD} 73^{+}$MDSCs was decreased with increasing numbers of chemotherapy cycles in the stable disease (SD) and partial response (PR) groups, whereas there was a trend toward an increase in the percentage of $\mathrm{CD} 39^{+} \mathrm{CD} 73^{+}$ MDSCs in the progressive disease (PD) group, suggesting that the changes in $\mathrm{CD}_{3} 9^{+} \mathrm{CD}_{3} 3^{+}$MDSC frequency in NSCLC patients may be sufficient for predicting chemotherapeutic response. The ectoenzymatic activities of CD39 and CD73 are required for MDSC-mediated suppressive and chemoprotective effects [21].

\section{The effect of radiotherapy on MDSCs}

Navarro-Martin et al. performed immunophenotypic analysis of peripheral blood samples from seven patients with LC who were unfit for surgery and treated with stereotactic body radiotherapy (SBRT). The study provided novel evidence that SBRT had a systemic effect on the immune system. The observation that both $\mathrm{CD} 33^{+} \mathrm{CD} 11 \mathrm{~b}^{+} \mathrm{CD} 14^{-}$PMN-MDSCs and $\mathrm{CD}_{3}{ }^{+} \mathrm{CD} 11 \mathrm{~b}^{+} \mathrm{CD} 14^{+} \mathrm{HLA}^{-D R^{-/ \text {low }}}$ M-MDSCs exhibited decreases in immunosuppressive function is a salient finding of the study [27].

\section{MDSCs are associated with the efficacy of immune checkpoint inhibitor treatment}

Based on the immunosuppressive function of MDSCs, these cells also play important roles in predicting the efficacy of anti-PD-1 therapy. It has been reported that the number of Lox-1 ${ }^{+}$PMN-MDSCs in nonresponders is significantly higher than that in responders after the 1st nivolumab treatment and that related factors involved in MDSC proliferation (CXCL2, CCL23, and CX3CL1) and recruitment (HMGB1) exhibit the same trend, suggesting that Lox $-1^{+}$PMN-MDSCs are a specific subset with immunosuppressive function in NSCLC patients. Patients with a relatively high ratio of Treg cells to Lox $-1^{+}$ PMN-MDSCs in the blood after their 1st nivolumab treatment will have improved PFS. The ratio of Treg cells to Lox-1 $1^{+}$PMN-MDSCs in the blood after the 1st nivolumab treatment predicts early response in NSCLC patients and may provide clinicians with vital information on whether to continue or stop further anti-PD-1 therapy [24]. Limagne et al. studied a prospective cohort of metastatic NSCLC patients $(n=61)$ treated with second- or third-line nivolumab. They observed that no variable was significantly associated with PFS under anti-PD-1 treatment at baseline; however, a high level of Tim-3 expression in peripheral lymphoid cells and an accumulation of $\mathrm{Lin}^{-} \mathrm{CD} 33^{+} \mathrm{CD} 14^{+} \mathrm{CD} 15^{-} \mathrm{HLA}^{-} \mathrm{DR}^{-} \mathrm{M}-$ MDSCs shortly after the initiation of therapy were important factors that negatively affected the response to anti-PD-1 therapy. Moreover, Tim-3 expression on $\mathrm{CD} 8^{+} \mathrm{T}$ cells and galectin-9 expression on M-MDSCs blunted the secretion of IFN $\gamma$ from $\mathrm{CD}^{+}$cells and were involved in the mechanisms of resistance to nivolumab
[25]. A study of 53 patients with NSCLC receiving nivolumab showed that patients with baseline high value of PMN-MDSCs ( $\geq 6$ cell $/ \mu \mathrm{l}$ ) had a significantly improved survival compared with those patients with a lower baseline data [26]. The results of MDSC's effects for the immune checkpoint inhibitor treatment are inconsistent, and thus, multicenter, mechanistic studies are needed to obtain more definitive results.

\section{MDSCs in murine models of LC}

Murine models are regularly used to study the relationship between MDSCs and LC. Chen et al. reported that the accumulation of MDSCs in aged mice and the expression of PD-L1 (B7-H1) on MDSCs were closely correlated with age. Inhibition of PD-L1 (B7-H1) significantly reactivated T cells and reduced the tumor progression mediated by MDSCs. In addition, IL-10 released in aged mice stimulated the expression of PD-L1 (B7-H1) on MDSCs [92]. Parallel increases in the level of galectin-3 and the number of MDSCs in vivo have been detected after cisplatin treatment [93]. Pulmonary carbon nanotube (CNT) aspiration was shown to render the host susceptible to lung carcinoma formation in a murine metastasis/dissemination model. This effect was mediated by increased local and systemic accumulation of MDSCs [94]. Subsequent studies further revealed that in vivo exposure to CNT rendered lung MDSCs susceptible to tumor-induced expression of TGF $\beta$, which was responsible for the inhibition of $\mathrm{T}$ cell activity by MDSCs [95]. Dajon et al., using a murine model of lung adenocarcinoma, found that stimulation of Toll-like receptor 7 (TLR7) expressed by adenocarcinoma cells modulated the immune infiltrate, leading to a significant expansion of MDSCs that was associated with increased secretion of CCL2 and GM-CSF in the tumor microenvironment. TLR7 stimulation had a prometastatic effect, while MDSC depletion drastically reduced the number of metastases. In line with the involvement of epithelial-mesenchymal transition (EMT) in the metastatic process, lung tumors expressing high levels of TLR7 have high expression of vimentin and low abundance of E-cadherin [96].

\section{Therapeutic MDSC-targeted strategies for inhibiting LC}

As described above, a large body of evidence supports a close association between MDSC accumulation and clinical outcomes in LC patients. A recent meta-analysis of studies of various solid tumor patients showed that MDSCs were significantly associated with OS and PFS [97]. MDSCs are associated with anticancer therapies, including bevacizumab [23], cisplatin and other chemotherapeutic drugs $[15,21,56]$, and recent studies have shown that MDSCs levels are associated with the response of patients to anti-PD-1 treatment [24, 25]. A variety of signaling pathways and cytokines are involved 
in the regulation of MDSCs. The interaction of all these factors constitutes a complex network control system that regulates the generation and function of MDSCs. To successfully implement anti-LC treatment, MDSCs, a major suppressive population in tumors, must be removed, so strategies targeting MDSCs are gradually being realized (Table 2). For example, the efficacy of therapeutic vaccination is increased when this approach is combined with MDSC depletion (anti-Gr1 antibody treatment) [9].

\section{All-trans retinoic acid}

All-trans retinoic acid (ATRA) was historically the first therapeutic compound used to target MDSCs [110]. In previous studies, ATRA showed a direct effect on MDSCs, causing apoptosis in PMN-MDSCs and differentiating MMDSCs into mature myeloid cells [110-112]. The effect of ATRA on MDSCs is linked to the upregulation of glutathione synthase and glutathione (GSH) expression in these cells. GSH dampens the level of ROS in MDSCs and thus promotes their differentiation [113]. Iclozan et al. found that for extensive SCLC, a combination of the P53 vaccine and ATRA reduced the proportion of Lin $^{-}$HLA$\mathrm{DR}^{-} \mathrm{CD} 33^{+}$MDSCs in the peripheral blood and increased the vaccine-induced immune response to nearly $42 \%$ [98].

\section{Bevacizumab}

In vivo and in vitro analyses have shown that VEGF released from the tumor microenvironment stimulates the mobilization of MDSCs from the bone marrow to the peripheral blood, thus leading to increased MDSC levels in the peripheral blood. In addition, VEGF contributes to the selective accumulation of MDSCs within tumor sites [114]. Therefore, VEGF may not only promote tumor growth but also participate in a suppressive process that limits antitumor immunity [115]. Bevacizumab has been demonstrated to provide a survival benefit when used in combination with platinum-based doublet chemotherapy in patients with nonsquamous NSCLC. For NSCLC patients, three cycles of bevacizumabcontaining regimens compared with non-bevacizumabbased regimens significantly reduced the percentage of PMN-MDSCs [23]. The combination of bevacizumab and an EGFR tyrosine kinase inhibitor (TKI) robustly improved the intracranial control rate and intracranial lesion time to progression (TTP) in patients with EGFRmutant lung adenocarcinoma, possibly by reducing the level of circulating S100A9-positive M-MDSCs, along with enhancing gene signatures associated with $\mathrm{CD} 8^{+} \mathrm{T}$ cell effector genes, Th1 chemokines, and NK cells [99].

\section{Dopamine D2 receptor agonists}

Studies have shown that dopamine (DA) stimulates the endocytosis of VEGFR-2 via dopamine D2 receptor (D2R), thereby preventing angiogenesis by inhibiting VEGF binding, receptor phosphorylation, and subsequent downstream signaling [116]. Subsequent studies by numerous investigators have clearly demonstrated that this strategy can be successfully applied to various diseases, including cancer $[117,118]$. Hoeppner et al. demonstrated that D2R agonists (Cabergoline) inhibited NSCLC tumor progression in orthotopic lung tumor models through two mechanisms: a reduction in tumor angiogenesis in lung endothelial cells and abrogation of tumor-infiltrating MDSCs [100].

\section{Cimetidine}

Cimetidine, a histamine type-2 receptor antagonist, is known to inhibit the growth of several tumors in humans and animals $[101,119,120]$. Zheng et al. found that cimetidine significantly inhibited tumor growth in 3LL lung tumor mouse models and reduced the accumulation of MDSCs in the spleen, blood, and tumor tissue. The underlying mechanisms were as follows: first, cimetidine affected the expression of Fas/FasL signaling in MDSCs; then, cimetidine induced apoptosis in MDSCs in a caspase-dependent manner [101].

\section{Superoxide dismutase mimetic}

MDSCs produce ROS-associated free radicals and immunoregulatory cytokines to inhibit host $\mathrm{CD}^{+}$and $\mathrm{CD}^{+} \mathrm{T}$ cell responses, thereby promoting tumor progression and metastasis $[7,121]$. In a mouse model of homologous LC, the combination of a superoxide dismutase mimetic (SOD mim) targeting ROS and gemcitabine not only impaired MDSC function and induced an effective memory $\mathrm{T}$ cell response against lung tumors but also reduced tumor growth and resulted in longterm immunity and survival. The cellular redoxmediated activation of STAT-3 and regulation of central memory and effector memory $\mathrm{CD}^{+} \mathrm{T}$ cell metabolism contributed to long-term immunity. Furthermore, adoptive transfer experiments demonstrated that inhibiting ROS produced by MDSCs and MDSCs enhanced the persistence of memory $\mathrm{CD}^{+} \mathrm{T}$ cells and their strong activity in response to re-exposure to tumor antigens during the relapse phase [102].

\section{Carnosic acid}

Liu et al. found that the drug carnosic acid, which has antioxidant and antibacterial properties, could inhibit the function of MDSCs in tumor models and enhance the anti-LC activity of cisplatin. The mechanism might involve decreased expression of Arg-1, iNOS2, and MMP9. In addition, in their experiments, $\mathrm{CD}^{+} \mathrm{T}$ cells were found to be present mainly in tumor tissues after treatment with carnosic acid. At the same time, the mRNA expression of Perforin, Granzyme B, and FasL was boosted, which might indicate that carnosic acid 
Yang et al. Journal of Hematology \& Oncology

(2020) 13:10

Page 10 of 17

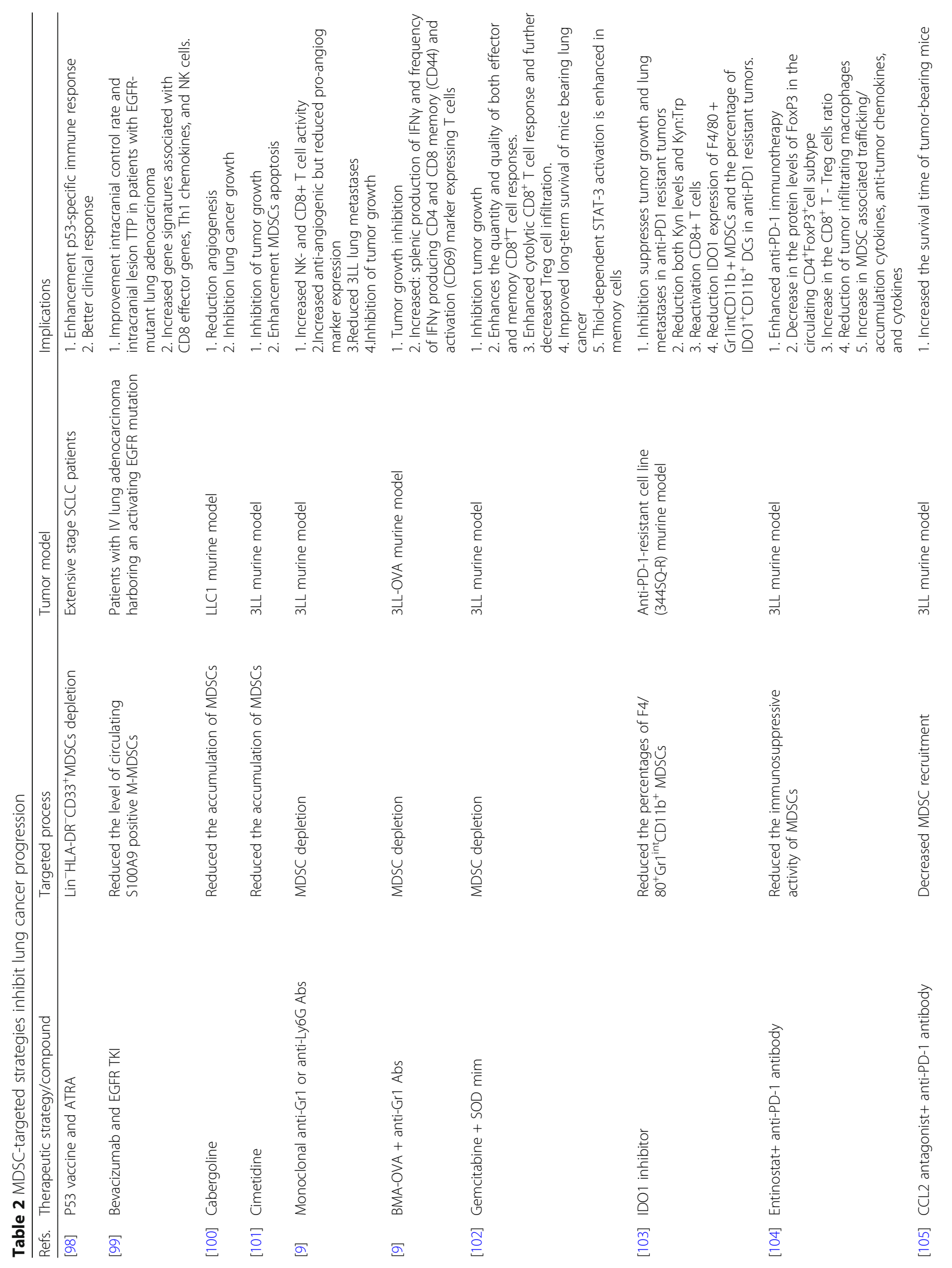


Yang et al. Journal of Hematology \& Oncology

(2020) 13:10

Page 11 of 17

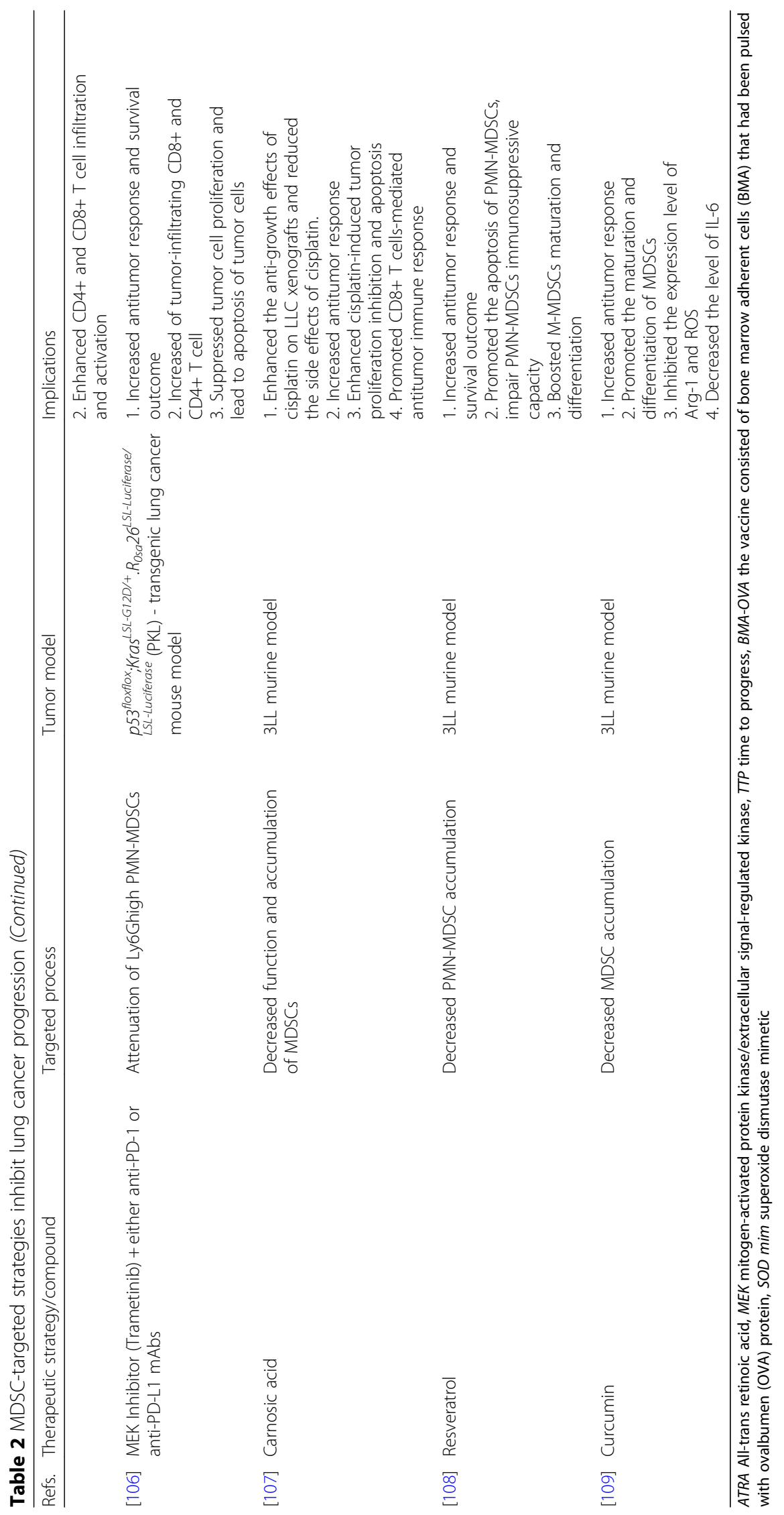


promoted the functions of $\mathrm{CD}^{+} \mathrm{T}$ cells and contributed to tumor suppression together with cisplatin. Therefore, carnosic acid may be a new candidate for LC combination therapy [107].

\section{Resveratrol}

Resveratrol (RSV) is a pleiotropic phytochemical found in peanuts and grapes that has been indicated to provide a wide range of health benefits, such as reducing oxidative, inflammatory, and apoptotic signals [122] - protecting against neurological decline [123], improving cardiovascular health [124], ameliorating diabetes [125], and preventing cancer [126]. The anticancer properties of RSV act through diverse molecular mechanisms that have been investigated in a plethora of cellular and animal models [127, 128]. Zhao et al. demonstrated for the first time that RSV could reduce the accumulation of MDSCs in vivo and in vitro while delaying the progression of cancer in LLC tumor-bearing murine models. In vitro results indicated that RSV attenuated PMN-MDSC expansion by selectively inducing apoptosis and the differentiation of M-MDSCs into Mø and reducing the recruitment of PMN-MDSCs [108]. These results indicate that RSV should be considered a modulator of MDSC suppressive function and that RSV is a novel potentiator for tumor immunotherapy.

\section{Curcumin}

Curcumin, a yellow substance derived from turmeric that belongs to the polyphenol superfamily, is a highly pleiotropic molecule. Curcumin combined with vaccination leads to decreased numbers of MDSCs and Treg cells, decreased levels of IL- 6 and an elevation in the $\mathrm{CD} 8^{+} \mathrm{T}$ cell population in an advanced melanoma model [129]. In LLC tumor models, a curcumin-based treatment strategy was shown to reduce the frequency and absolute number of MDSCs in the spleen and tumor tissues, significantly reduce IL-6 levels in tumor tissues and the serum, weaken the Arg-1 expression level and ROS production in MDSCs purified from tumor tissue in vivo, and promote the expression of the maturation markers F4/80, MHCII, CD11c, and CD80 on MDSCs in tumors. Since IL- 6 could promote the expansion and suppressive function of MDSCs [130], it was suggested that curcumin might inhibit the accumulation and suppressive function of MDSCs partly by reducing the level of IL-6 in tumor-bearing mice [109].

\section{Increased immune checkpoint inhibitor efficacy}

In addition to the abovedescribed therapies, immune checkpoint inhibition is a novel treatment that is being studied extensively in LC. Many of the studies have concluded that MDSCs are associated with resistance to anti-PD-1 therapy $[24,25]$ and that there is an elevated level of PD-L1 expression on MDSCs [28]; thus, targeting MDSCs has the potential to increase anti-PD-1 efficacy. Studies by Li et al. provided preclinical evidence that anti-PD1 resistance in LC was associated with overexpression of IDO1 in $\mathrm{F} 4 / 80^{+} \mathrm{Gr} 1^{\text {int }} \mathrm{CD} 11 \mathrm{~b}^{+}$MDSCs. Treatment with an IDO1 inhibitor (INCB023843) reduced IDO1 expression and blocked the accumulation of $\mathrm{F} 4 / 80^{+} \mathrm{Gr} 1^{\text {int }} \mathrm{CD} 11 \mathrm{~b}^{+} \mathrm{MDSCs}$, resulting in reactivation of the antitumor immune response. Thus, IDO1 inhibition represents another immunotherapeutic strategy to overcome the immunosuppressive TIME in anti-PD1 therapy-resistant tumors [103]. Entinostat is an oral, class I-specific histone deacetylase inhibitor (HDACi) that disrupts the dynamic interactions between the tumor microenvironment and host immune surveillance [131]. Orillion and colleagues used entinostat in combination with PD-1 inhibitors to reduce tumor growth and increase survival in subcutaneous LC models. The underlying mechanisms of this combination might be significant decreases in the arginase- 1 , iNOS, and COX2 levels and changes in the cytokines/chemokines released in vivo with a shift from an immunosuppressive microenvironment to an immunostimulatory microenvironment [104]. Wang et al. showed that MDSC subsets had a positive correlation with CCL2. In addition, combination treatment with a CCL2 antagonist and anti-PD1 antibody enhanced $\mathrm{CD} 4^{+}$and $\mathrm{CD}^{+} \mathrm{T}$ cell infiltration, as well as the production of IFN $\gamma$, and increased the survival time of tumor-bearing mice [105]. KRAS mutations, known as oncogenic driver mutations, have been detected in 20 40\% of adenocarcinomas and in $3 \sim 6 \%$ of squamous cell carcinomas [132]. Targeting the downstream target of KRAS signaling, mitogenactivated protein kinase/extracellular signal-regulated kinase (MEK) in KRAS-mutated NSCLC has been reported to be largely ineffective [133, 134]. However, the combination of a reduced dose of a MEK inhibitor and an immune checkpoint inhibitor for treatment of a Kras/ p53-driven lung tumor was shown to significantly prevent tumor growth and extend survival in preclinical models. In addition, the mechanisms may be as follows: (1) enhancing $\mathrm{T}$ cell infiltration both in the tumor microenvironment and inside the tumor bed, (2) decreasing the number of PMN-MDSCs in the tumor, and (3) suppressing tumor cell proliferation and leading to apoptosis in tumor cells [106].

\section{CD33 antibody}

The anti-MDSC methods described above are either based on mouse models or do not have a selective depleting effect on human MDSCs, but rather extensive immune regulation. Therefore, we need to explore the intentional marker for human MDSCs as a better way to consume MDSCs. CD33, a defining marker of MDSCs $\left(\mathrm{CD} 33^{+}\right.$HLA$\mathrm{DR}^{-} \mathrm{Lin}^{-}$), is highly expressed in myelodysplastic syndrome 
(MDS) MDSCs. Eksioglu et al. took advantage of the novel, fully human CD33 antibody BI 836858, which is Fcengineered for increased binding to $\mathrm{Fc} \gamma$ receptor IIIa (FcyRIIIa), and observed that BI 836858 can reduce MDS MDSCs through antibody-dependent cellular cytotoxicity (ADCC) and that this effect is correlated with increases in granule mobilization and cell death. BI 836858 can also reduce both ROS and the levels of double-strand breaks and adducts [135]. One of the main challenges in targeting human MDSCs is their heterogeneity, as well as differences in immune phenotypes and intracellular suppression mechanisms between the same patient (blood and tumor) and across different types of cancer. Fultang et al. identified CD33 as a therapeutic target on peripheral and infiltrating MDSCs across cancer subtypes by RNA-sequencing and flow cytometry. Gemtuzumab ozogamicin (GO), a humanized anti-CD33 IgG4 mAb conjugated to a cytotoxic agent $\mathrm{N}$-acetyl gamma calicheamicin via an acid-labile hydrazone linker [136], has been successfully used as a treatment for acute myeloid leukemia [137]. The argeting of MDSCs with GO leads to GO internalization, increased p-ATM, and MDSC cell death. Anti-GD2-/mesothelin-/EGFRvIII-CAR$T$ cell activity is enhanced in combination with the antiMDSC effects of GO [138]. This research suggests that, for patients with high levels of MDSCs, immune "cold" tumors may be transferred into immune "hot" tumors via GO therapy to improve the efficacy of chemotherapeutic and/or immunotherapeutic regimens.

Both of the above studies consider that CD33 is a specific marker for human MDSCs and has a significant effect on depleting MDSCs. These two studies provide a better support for targeting the immunosuppressive TIME of LC patients.

\section{Conclusions}

Tumor cells develop a variety of mechanisms to evade the immune system and undergo progression. One of the key mechanisms is the establishment of an immunosuppressive TIME, in which MDSCs play a crucial role. There is increasing evidence that MDSCs are involved in the development of LC and may be used to predict the efficacy of immune checkpoint blockade treatment, but there are still a wide range of unknown mechanisms and interactions that require further research within this topic. Based on the description herein, various preclinical and clinical studies have shown the beneficial effects of altering the function and biology of MDSCs. These findings suggest that targeting MDSCs may be a promising strategy for use with existing immunotherapeutic strategies, such as boosting the immune system by vaccination or immune checkpoint inhibition. Using these strategies to treat LC may produce more breakthroughs that overcome current treatment limitations. However, these findings still require a more solid research foundation before clinical translation.
First, unlike other immunosuppressive cells (e.g., Treg cells and TAMs), MDSCs do not have a uniform molecular phenotype. Second, the results for the relationships between different MDSC subtypes and the prognosis of LC are not consistent. For example, some studies suggest that elevated PMN-MDSC numbers are an indicator of a poor prognosis [20, 24], while other studies show that MMDSCs have a better prognostic value than PMN-MDSCs $[15,22,25]$. Third, although MDSCs can be detected in the peripheral blood and tumor tissue, it is difficult to use the level of MDSCs in the peripheral blood to represent the distribution in tumor tissues, and the functional level is not predictable. Therefore, more in-depth explorations of the mechanisms of MDSCs in tumor tissues are still needed for LC patients. Finally, reasonable pharmacological data related to targeted MDSC therapy remain unresolved. It is hoped that this topic will be analyzed using a comprehensive epidemiological model to fully understand the value of collecting MDSC measurements for patient outcomes and to reduce the number of potential modifiable factors for MDSC accumulation in LC patients. Additional in-depth institutional studies will provide a more reliable basis for MDSC targeting either alone or in combination with chemotherapeutic and/or immunotherapeutic regimens.

\section{Abbreviations \\ Arg-1: Arginase 1; CARD9: Caspase recruitment domain-containing protein 9; CDK4: Cyclin-dependent kinase 4; DCs: Dendritic cells; EMT: Epithelial- mesenchymal transition; HDAC: Endogenous inhibitor of histone deacetylases; HIF-1a: Hypoxia-inducible factor-1a; iNOS: Inducible nitric oxide synthase; LC: Lung cancer; MDSCs: Myeloid-derived suppressor cells; M- MDSCs: Monocytic-MDSCs; Mø: Macrophages; NF-KB: Nuclear factor-KB; NOS2: Nitric oxide synthase 2; NSCLC: Non-small cell lung cancer; PMN MDSCs: Polymorphonuclear-MDSCs; ROS: Reactive oxygen species; SCLC: Small cell lung cancer; STAT: Signal transducer and activator of transcription; TAMs: Tumor-associated macrophages; TF: Tissue factor; TIME: Tumor immune microenvironment; TLR7: Toll-like receptor 7; Treg: Regulatory T; VEGF: Vascular endothelial growth factor}

Acknowledgements

Not applicable.

\section{Authors' contributions}

ZY and JG drafted the manuscript and contributed equally to the manuscript. LW discussed and revised the manuscript. WT, SJ, and WM designed the study and provided critical suggestions. All authors read and approved the final manuscript.

\section{Funding}

This study was conducted with support from the National Natural Science Foundation of China (No. 31570917).

Availability of data and materials

The dataset supporting the conclusions of this article is included within the article.

Ethics approval and consent to participate

This is not applicable for this review.

Consent for publication

This is not applicable for this review. 


\section{Competing interests}

The authors declare that they have no competing interests.

\section{Author details \\ ${ }^{1}$ Department of Oncology, The First Affiliated Hospital of Zhengzhou University, NO.1 Eastern Jianshe Road, Zhengzhou 450052, Henan, China. ${ }^{2}$ Department of Cardiology, The First Affiliated Hospital of Zhengzhou University, Zhengzhou 450052, Henan, China. ${ }^{3}$ Henan Province Key Laboratory of Cardiac Injury and Repair, Zhengzhou 450052, Henan, China. ${ }^{4}$ Departments of Otolaryngology, The Second Affiliated Hospital of Zhengzhou University, Zhengzhou 450000, Henan, China. ${ }^{5}$ Center for Precision Medicine of Zhengzhou University, NO.40 North Daxue Road, Zhengzhou 450052, Henan, China.}

Received: 4 November 2019 Accepted: 15 January 2020 Published online: 31 January 2020

\section{References}

1. Bray F, Ferlay J, Soerjomataram I, Siegel RL, Torre LA, Jemal A. Global cancer statistics 2018: GLOBOCAN estimates of incidence and mortality worldwide for 36 cancers in 185 countries. CA Cancer J Clin. 2018;68(6):394-424.

2. Milette S, Fiset PO, Walsh LA, Spicer JD, Quail DF. The innate immune architecture of lung tumors and its implication in disease progression. J Pathol. 2019:247(5):589-605.

3. Adah D, Hussain M, Qin L, Qin L, Zhang J, Chen X. Implications of MDSCstargeting in lung cancer chemo-immunotherapeutics. Pharmacol Res. 2016; 110:25-34

4. Tavakkoli M, Wilkins CR, Mones JV, Mauro MJ. A novel paradigm between leukocytosis, G-CSF secretion, neutrophil-to-lymphocyte ratio, myeloidderived suppressor cells, and prognosis in non-small cell lung cancer. Front Oncol. 2019:9:295.

5. Talmadge JE, Gabrilovich DI. History of myeloid-derived suppressor cells. Nat Rev Cancer. 2013;13(10):739-52.

6. Bronte V, Brandau S, Chen SH, Colombo MP, Frey AB, Greten TF Mandruzzato S, Murray PJ, Ochoa A, Ostrand-Rosenberg S, et al. Recommendations for myeloid-derived suppressor cell nomenclature and characterization standards. Nat Commun. 2016;7:12150.

7. Gabrilovich DI. Myeloid-derived suppressor cells. Cancer Immunol Res. 2017;5(1):3-8.

8. Ortiz ML, Lu L, Ramachandran I, Gabrilovich DI. Myeloid-derived suppressor cells in the development of lung cancer. Cancer Immunol Res. 2014;2(1):50-8.

9. Srivastava MK, Zhu L, Harris-White M, Kar UK, Huang M, Johnson MF, Lee JM, Elashoff D, Strieter R, Dubinett S, et al. Myeloid suppressor cell depletion augments antitumor activity in lung cancer. PLoS One. 2012;7(7):e40677.

10. Mandruzzato S, Brandau S, Britten CM, Bronte V Damuzzo V Gouttefangeas C, Maurer D, Ottensmeier C, van der Burg SH, Welters MJ, et al. Toward harmonized phenotyping of human myeloid-derived suppressor cells by flow cytometry: results from an interim study. Cancer Immunol mmunother 2016:65(2):161-9.

11. Ueha S, Shand FH, Matsushima K. Myeloid cell population dynamics in healthy and tumor-bearing mice. Int Immunopharmacol. 2011;11(7):783-8.

12. Elliott LA, Doherty GA, Sheahan K, Ryan EJ. Human tumor-infiltrating myeloid cells: phenotypic and functional diversity. Front Immunol. 2017;8:86.

13. Dumitru CA, Moses K, Trellakis S, Lang S, Brandau S. Neutrophils and granulocytic myeloid-derived suppressor cells: immunophenotyping, cell biology and clinical relevance in human oncology. Cancer Immunol Immunother. 2012;61(8):1155-67.

14. Liu CY, Wang YM, Wang CL, Feng PH, Ko HW, Liu YH, Wu YC, Chu Y, Chung $\mathrm{FT}$, Kuo $\mathrm{CH}$, et al. Population alterations of L-arginase- and inducible nitric oxide synthase-expressed CD11b+/CD14(-)/CD15+/CD33+ myeloid-derived suppressor cells and CD8+ T lymphocytes in patients with advanced-stage non-small cell lung cancer. J Cancer Res Clin Oncol. 2010;136(1):35-45.

15. Feng PH, Lee KY, Chang YL, Chan YF, Kuo LW, Lin TY, Chung FT, Kuo CS, Yu CT, Lin SM, et al. CD14(+)S100A9(+) monocytic myeloid-derived suppressor cells and their clinical relevance in non-small cell lung cancer. Am J Respir Crit Care Med. 2012;186(10):1025-36.

16. Heuvers ME, Muskens F, Bezemer K, Lambers M, Dingemans AM, Groen $H J$, Smit EF, Hoogsteden HC, Hegmans JP, Aerts JG. Arginase-1 mRNA expression correlates with myeloid-derived suppressor cell levels in peripheral blood of NSCLC patients. Lung Cancer. 2013;81(3):468-74.

17. Huang A, Zhang B, Wang B, Zhang F, Fan KX, Guo YJ. Increased CD14(+ )HLA-DR (-/low) myeloid-derived suppressor cells correlate with extrathoracic metastasis and poor response to chemotherapy in non-small cell lung cancer patients. Cancer Immunol Immunother. 2013;62(9):1439-51.

18. Tian T, Gu X, Zhang B, Liu Y, Yuan C, Shao L, Guo Y, Fan K. Increased circulating CD14(+)HLA-DR-/low myeloid-derived suppressor cells are associated with poor prognosis in patients with small-cell lung cancer. Cancer Biomark. 2015;15(4):425-32.

19. Zhang G, Huang H, Zhu Y, Yu G, Gao X, Xu Y, Liu C, Hou J, Zhang X. A novel subset of B7-H3(+)CD14(+)HLA-DR(-/low) myeloid-derived suppressor cells are associated with progression of human NSCLC. Oncoimmunology. 2015;4(2):e977164

20. de Goeje PL, Bezemer K, Heuvers ME, Dingemans AC, Groen HJ, Smit EF, Hoogsteden HC, Hendriks RW, Aerts JG, Hegmans JP. Immunoglobulin-like transcript 3 is expressed by myeloid-derived suppressor cells and correlates with survival in patients with non-small cell lung cancer. Oncoimmunology. 2015:4(7):e1014242.

21. Li J, Wang L, Chen X, Li L, Li Y, Ping Y, Huang L, Yue D, Zhang Z, Wang F, et al. CD39/CD73 upregulation on myeloid-derived suppressor cells via TGFbeta-mTOR-HIF-1 signaling in patients with non-small cell lung cancer. Oncoimmunology. 2017:6(6):e1320011.

22. Vetsika EK, Koinis F, Gioulbasani M, Aggouraki D, Koutoulaki A, Skalidaki E, Mavroudis D, Georgoulias V, Kotsakis A. A circulating subpopulation of monocytic myeloid-derived suppressor cells as an independent prognostic/ predictive factor in untreated non-small lung cancer patients. J Immunol Res. 2014:2014:659294

23. Koinis F, Vetsika EK, Aggouraki D, Skalidaki E, Koutoulaki A, Gkioulmpasani M, Georgoulias V, Kotsakis A. Effect of first-line treatment on myeloid-derived suppressor cells' subpopulations in the peripheral blood of patients with non-small cell lung cancer. J Thorac Oncol. 2016;11(8):1263-72.

24. Kim HR, Park SM, Seo SU, Jung I, Yoon HI, Gabrilovich DI, Cho BC, Seong SY, Ha SJ, Youn JI. The ratio of peripheral regulatory T cells to Lox-1(+) Polymorphonuclear myeloid-derived suppressor cells predicts the early response to anti-PD-1 therapy in patients with non-small cell lung cancer. Am J Respir Crit Care Med. 2019;199(2):243-6.

25. Limagne E, Richard C, Thibaudin M, Fumet JD, Truntzer C, Lagrange A Favier L, Coudert B, Ghiringhelli F. Tim-3/galectin-9 pathway and mMDSC control primary and secondary resistances to PD-1 blockade in lung cancer patients. Oncoimmunology. 2019;8(4):e1564505.

26. Passaro A, Mancuso P, Gandini S, Spitaleri G, Labanca V, Guerini-Rocco E, Barberis M, Catania C, Del Signore E, de Marinis F, et al. Gr-MDSC-linked asset as a potential immune biomarker in pretreated NSCLC receiving nivolumab as second-line therapy. Clin Transl Oncol. 2019. https://doi.org/ 10.1007/s12094-019-02166-Z

27. Navarro-Martin A, Galiana IL, Berenguer Frances MA, Cacicedo J, Canas Cortes R, Comas Anton S, Padrones Sanchez S, Bolivar Cuevas S, Parry R, Guedea Edo F. Preliminary study of the effect of stereotactic body radiotherapy (SBRT) on the immune system in lung cancer patients unfit for surgery: immunophenotyping analysis. Int J Mol Sci. 2018;19(12). https://doi. org/10.3390/ijms19123963.

28. Yamauchi Y, Safi S, Blattner C, Rathinasamy A, Umansky L, Juenger S, Warth A, Eichhorn M, Muley T, Herth FJF, et al. Circulating and tumor myeloidderived suppressor cells in resectable non-small cell lung cancer. Am J. Respir Crit Care Med. 2018;198(6):777-87.

29. Han X, Shi H, Sun Y, Shang C, Luan T, Wang D, Zeng X, Ba X. CXCR2 expression on granulocyte and macrophage progenitors under tumor conditions contributes to mo-MDSC generation via SAP18/ERK/STAT3. Cell Death Dis. 2019:10(8):598.

30. Kumar V, Cheng P, Condamine T, Mony S, Languino LR, McCaffrey JC, Hockstein N, Guarino M, Masters G, Penman E, et al. CD45 phosphatase inhibits STAT3 transcription factor activity in myeloid cells and promotes tumor-associated macrophage differentiation. Immunity. 2016:44(2):303-15.

31. Shime H, Kojima A, Maruyama A, Saito Y, Oshiumi H, Matsumoto M, Seya T. Myeloid-derived suppressor cells confer tumor-suppressive functions on natural killer cells via polyinosinic:polycytidylic acid treatment in mouse tumor models. J Innate Immun. 2014:6(3):293-305.

32. Bruno A, Mortara L, Baci D, Noonan DM, Albini A. Myeloid derived suppressor cells interactions with natural killer cells and pro-angiogenic activities: roles in tumor progression. Front Immunol. 2019;10:771.

33. Shu CC, Pan SW, Feng JY, Wang JY, Chan YJ, Yu CJ, Su WJ. The clinical significance of programmed death-1, regulatory $T$ cells and myeloid derived suppressor cells in patients with nontuberculous mycobacteria-lung disease. J Clin Med. 2019;8(5). https://doi.org/10.3390/jcm8050736. 
34. Wang Y, Schafer CC, Hough KP, Tousif S, Duncan SR, Kearney JF, Ponnazhagan S, Hsu HC, Deshane JS. Myeloid-derived suppressor cells impair B cell responses in lung cancer through IL-7 and STAT5. J Immunol. 2018:201(1):278-95.

35. Ostrand-Rosenberg S, Sinha P, Beury DW, Clements VK. Cross-talk between myeloid-derived suppressor cells (MDSC), macrophages, and dendritic cells enhances tumor-induced immune suppression. Semin Cancer Biol. 2012; 22(4):275-81.

36. Kumar V, Patel S, Tcyganov E, Gabrilovich DI. The nature of myeloid-derived suppressor cells in the tumor microenvironment. Trends Immunol. 2016; 37(3):208-20.

37. Safarzadeh E, Orangi M, Mohammadi H, Babaie F, Baradaran B. Myeloidderived suppressor cells: important contributors to tumor progression and metastasis. J Cell Physiol. 2018;233(4):3024-36.

38. Sica A, Strauss L. Energy metabolism drives myeloid-derived suppressor cell differentiation and functions in pathology. J Leukoc Biol. 2017;102(2):325-34.

39. Rodriguez PC, Zea AH, Culotta KS, Zabaleta J, Ochoa JB, Ochoa AC. Regulation of T cell receptor CD3zeta chain expression by L-arginine. J Bio Chem. 2002;277(24):21123-9.

40. Rodriguez PC, Quiceno DG, Ochoa AC. L-arginine availability regulates Tlymphocyte cell-cycle progression. Blood. 2007;109(4):1568-73.

41. Fletcher M, Ramirez ME, Sierra RA, Raber $P$, Thevenot $P$, Al-Khami AA, Sanchez-Pino D, Hernandez C, Wyczechowska DD, Ochoa AC, et al. Larginine depletion blunts antitumor T-cell responses by inducing myeloidderived suppressor cells. Cancer Res. 2015;75(2):275-83.

42. Xue $\mathrm{Q}$, Yan $\mathrm{Y}$, Zhang $\mathrm{R}$, Xiong $\mathrm{H}$. Regulation of iNOS on immune cells and its role in diseases. Int J Mol Sci. 2018;19(12). https://doi.org/10.3390/ ijms19123805.

43. Garcia-Ortiz A, Serrador JM. Nitric oxide signaling in T cell-mediated immunity. Trends Mol Med. 2018;24(4):412-27.

44. Nagaraj S, Schrum AG, Cho HI, Celis E, Gabrilovich DI. Mechanism of T cell tolerance induced by myeloid-derived suppressor cells. J Immunol. 2010; 184(6):3106-16.

45. Latham T, Mackay L, Sproul D, Karim M, Culley J, Harrison DJ, Hayward L, Langridge-Smith P, Gilbert N, Ramsahoye BH. Lactate, a product of glycolytic metabolism, inhibits histone deacetylase activity and promotes changes in gene expression. Nucleic Acids Res. 2012;40(11):4794-803.

46. Husain Z, Huang Y, Seth P, Sukhatme VP. Tumor-derived lactate modifies antitumor immune response: effect on myeloid-derived suppressor cells and NK cells. J Immunol. 2013;191(3):1486-95.

47. Liu G, Bi Y, Shen B, Yang H, Zhang Y, Wang X, Liu H, Lu Y, Liao J, Chen X, et al. SIRT1 limits the function and fate of myeloid-derived suppressor cells in tumors by orchestrating HIF-1alpha-dependent glycolysis. Cancer Res. 2014;74(3):727-37.

48. Zhang B. CD73: a novel target for cancer immunotherapy. Cancer Res. 2010; 70(16):6407-11.

49. Allard B, Longhi MS, Robson SC, Stagg J. The ectonucleotidases CD39 and CD73: novel checkpoint inhibitor targets. Immunol Rev. 2017;276(1):121-44.

50. Li L, Wang L, Li J, Fan Z, Yang L, Zhang Z, Zhang C, Yue D, Qin G, Zhang T, et al. Metformin-induced reduction of CD39 and CD73 blocks myeloidderived suppressor cell activity in patients with ovarian cancer. Cancer Res. 2018;78(7):1779-91.

51. Lee JK, Won C, Yi EH, Seok SH, Kim MH, Kim SJ, Chung MH, Lee HG, Ikuta K, Ye SK. Signal transducer and activator of transcription 3 (Stat3) contributes to T-cell homeostasis by regulating pro-survival $\mathrm{BCl}-2$ family genes. Immunology. 2013;140(3):288-300.

52. Li Y, Du H, Qin Y, Roberts J, Cummings OW, Yan C. Activation of the signal transducers and activators of the transcription 3 pathway in alveolar epithelial cells induces inflammation and adenocarcinomas in mouse lung. Cancer Res. 2007:67(18):8494-503.

53. Wu L, Du H, Li Y, Qu P, Yan C. Signal transducer and activator of transcription 3 (Stat3C) promotes myeloid-derived suppressor cell expansion and immune suppression during lung tumorigenesis. Am J Pathol. 2011;179(4):2131-41.

54. Burke MC, Oei MS, Edwards NJ, Ostrand-Rosenberg S, Fenselau C. Ubiquitinated proteins in exosomes secreted by myeloid-derived suppressor cells. J Proteome Res. 2014;13(12):5965-72.

55. Tian X, Shen H, Li Z, Wang T, Wang S. Tumor-derived exosomes, myeloid-derived suppressor cells, and tumor microenvironment. J Hematol Oncol. 2019;12(1):84.

56. Deng Z, Rong Y, Teng Y, Zhuang X, Samykutty A, Mu J, Zhang L, Cao P, Yan J, Miller D, et al. Exosomes miR-126a released from MDSC induced by DOX treatment promotes lung metastasis. Oncogene. 2017;36(5):639-51.
57. Ridder K, Sevko A, Heide J, Dams M, Rupp AK, Macas J, Starmann J, Tjwa M, Plate $\mathrm{KH}$, Sultmann $\mathrm{H}$, et al. Extracellular vesicle-mediated transfer of functional RNA in the tumor microenvironment. Oncoimmunology. 2015;4(6):e1008371.

58. Hara H, Ishihara C, Takeuchi A, Imanishi T, Xue L, Morris SW, Inui M, Takai T, Shibuya A, Saijo S, et al. The adaptor protein CARD9 is essential for the activation of myeloid cells through ITAM-associated and Toll-like receptors. Nat Immunol. 2007;8(6):619-29.

59. Ruland J. CARD9 signaling in the innate immune response. Ann N Y Acad Sci. 2008;1143:35-44

60. Drummond RA, Franco LM, Lionakis MS. Human CARD9: a critical molecule of fungal immune surveillance. Front Immunol. 2018;9:1836.

61. Zhong X, Chen B, Yang L, Yang Z. Molecular and physiological roles of the adaptor protein CARD9 in immunity. Cell Death Dis. 2018;9(2):52.

62. Qu J, Liu L, Xu Q, Ren J, Xu Z, Dou H, Shen S, Hou Y, Mou Y, Wang T. CARD9 prevents lung cancer development by suppressing the expansion of myeloid-derived suppressor cells and IDO production. Int J Cancer. 2019; 145(8):2225-37.

63. Chen ZH, Wang WT, Huang W, Fang K, Sun YM, Liu SR, Luo XQ, Chen YQ. The IncRNA HOTAIRM1 regulates the degradation of PML-RARA oncoprotein and myeloid cell differentiation by enhancing the autophagy pathway. Cell Death Differ. 2017;24(2):212-24.

64. Wei S, Zhao M, Wang X, Li Y, Wang K. PU.1 controls the expression of long noncoding RNA HOTAIRM1 during granulocytic differentiation. J Hematol Oncol. 2016;9(1):44.

65. Tian X, Ma J, Wang T, Tian J, Zhang Y, Mao L, Xu H, Wang S. Long noncoding RNA HOXA transcript antisense RNA myeloid-specific 1-HOXA1 axis downregulates the immunosuppressive activity of myeloid-derived suppressor cells in lung cancer. Front Immunol. 2018;9:473.

66. Zhang $\mathrm{X}$, Hamblin $\mathrm{MH}$, Yin KJ. The long noncoding RNA Malat1: its physiological and pathophysiological functions. RNA Biol. 2017;14(12):1705-14.

67. Tripathi V, Shen Z, Chakraborty A, Giri S, Freier SM, Wu X, Zhang Y, Gorospe M, Prasanth SG, Lal A, et al. Long noncoding RNA MALAT1 controls cell cycle progression by regulating the expression of oncogenic transcription factor B-MYB. PLoS Genet. 2013;9(3):e1003368.

68. Lin N, Yao Z, Xu M, Chen J, Lu Y, Yuan L, Zhou S, Zou X, Xu R. Long noncoding RNA MALAT1 potentiates growth and inhibits senescence by antagonizing ABI3BP in gallbladder cancer cells. J Exp Clin Cancer Res. 2019;38(1):244.

69. Schmidt LH, Spieker T, Koschmieder S, Schaffers S, Humberg J, Jungen D, Bulk E, Hascher A, Wittmer D, Marra A, et al. The long noncoding MALAT-1 RNA indicates a poor prognosis in non-small cell lung cancer and induces migration and tumor growth. J Thorac Oncol. 2011;6(12):1984-92.

70. Zhou Q, Tang X, Tian X, Tian J, Zhang Y, Ma J, Xu H, Wang S. LncRNA MALAT1 negatively regulates MDSCS in patients with lung cancer. J Cancer. 2018;9(14):2436-42.

71. Tian X, Ma J, Wang T, Tian J, Zheng Y, Peng R, Wang Y, Zhang Y, Mao L, Xu $\mathrm{H}$, et al. Long non-coding RNA RUNXOR accelerates MDSC-mediated immunosuppression in lung cancer. BMC Cancer. 2018;18(1):660.

72. Zheng Y, Tian X, Wang T, Xia X, Cao F, Tian J, Xu P, Ma J, Xu H, Wang S. Long noncoding RNA Pvt1 regulates the immunosuppression activity of granulocytic myeloid-derived suppressor cells in tumor-bearing mice. Mol Cancer. 2019;18(1):61.

73. Su Y, Qiu Y, Qiu Z, Qu P. MicroRNA networks regulate the differentiation, expansion and suppression function of myeloid-derived suppressor cells in tumor microenvironment. J Cancer. 2019;10(18):4350-6.

74. Li L, Zhang J, Diao W, Wang D, Wei Y, Zhang CY, Zen K. MicroRNA-155 and microRNA-21 promote the expansion of functional myeloid-derived suppressor cells. J Immunol. 2014;192(3):1034-43.

75. Wang J, Yu F, Jia X, Iwanowycz S, Wang Y, Huang S, Ai W, Fan D. MicroRNA155 deficiency enhances the recruitment and functions of myeloid-derived suppressor cells in tumor microenvironment and promotes solid tumor growth. Int J Cancer. 2015;136(6):E602-13.

76. Tian J, Rui K, Tang X, Ma J, Wang Y, Tian X, Zhang Y, Xu H, Lu L, Wang S. MicroRNA-9 regulates the differentiation and function of myeloid-derived suppressor cells via targeting Runx1. J Immunol. 2015;195(3):1301-11.

77. Goldin-Lang P, Tran QV, Fichtner I, Eisenreich A, Antoniak S, Schulze K, Coupland SE, Poller W, Schultheiss HP, Rauch U. Tissue factor expression pattern in human non-small cell lung cancer tissues indicate increased blood thrombogenicity and tumor metastasis. Oncol Rep. 2008:20(1):123-8.

78. Liu S, Zhang Y, Zhao X, Wang J, Di C, Zhao Y, Ji T, Cheng K, Wang Y, Chen L, et al. Tumor-specific silencing of tissue factor suppresses metastasis and prevents cancer-associated hypercoagulability. Nano Lett. 2019;19(7):4721-30. 
79. Han X, Zha H, Yang F, Guo B, Zhu B. Tumor-derived tissue factor aberrantly activates complement and facilitates lung tumor progression via recruitment of myeloid-derived suppressor cells. Int J Mol Sci. 2017;18(1). https://doi.org/10.3390/ijms18010022.

80. Condamine T, Kumar V, Ramachandran IR, Youn Jl, Celis E, Finnberg N, ElDeiry WS, Winograd R, Vonderheide RH, English NR, et al. ER stress regulates myeloid-derived suppressor cell fate through TRAlL-R-mediated apoptosis. J Clin Invest. 2014:124(6):2626-39.

81. Peng D, Tanikawa T, Li W, Zhao L, Vatan L, Szeliga W, Wan S, Wei S, Wang Y, Liu Y, et al. Myeloid-derived suppressor cells endow stem-like qualities to breast cancer cells through IL6/STAT3 and NO/NOTCH cross-talk signaling. Cancer Res. 2016;76(11):3156-65.

82. Ai L, Mu S, Sun C, Fan F, Yan H, Qin Y, Cui G, Wang Y, Guo T, Mei H, et al. Myeloid-derived suppressor cells endow stem-like qualities to multiple myeloma cells by inducing piRNA-823 expression and DNMT3B activation. Mol Cancer. 2019;18(1):88.

83. Scrimini S, Pons J, Agusti A, Clemente A, Sallan MC, Bauca JM, Soriano JB, Cosio BG, Lopez M, Crespi C, et al. Expansion of myeloid-derived suppressor cells in chronic obstructive pulmonary disease and lung cancer: potential link between inflammation and cancer. Cancer Immunol Immunother. 2015; 64(10):1261-70.

84. Colonna M, Nakajima H, Navarro F, Lopez-Botet M. A novel family of Ig-like receptors for HLA class I molecules that modulate function of lymphoid and myeloid cells. J Leukoc Biol. 1999;66(3):375-81.

85. Cheng H, Mohammed F, Nam G, Chen Y, Qi J, Garner LI, Allen RL, Yan J, Willcox BE, Gao GF. Crystal structure of leukocyte Ig-like receptor LILRB4 (ILT3/LIR-5/CD85k): a myeloid inhibitory receptor involved in immune tolerance. J Biol Chem. 2011;286(20):18013-25.

86. Suciu-Foca N, Cortesini R. Central role of ILT3 in the T suppressor cell cascade. Cell Immunol. 2007;248(1):59-67.

87. Vlad G, Chang CC, Colovai Al, Vasilescu ER, Cortesini R, Suciu-Foca N. Membrane and soluble ILT3 are critical to the generation of T suppressor cells and induction of immunological tolerance. Int Rev Immunol. 2010; 29(2):119-32.

88. Perrot I, Michaud HA, Giraudon-Paoli M, Augier S, Docquier A, Gros L, Courtois R, Dejou C, Jecko D, Becquart O, et al. Blocking antibodies targeting the CD39/ CD73 immunosuppressive pathway unleash immune responses in combination cancer therapies. Cell Rep. 2019;27(8):2411-25 e2419.

89. Linden J, Koch-Nolte F, Dahl G. Purine release, metabolism, and signaling in the inflammatory response. Annu Rev Immunol. 2019;37:325-47.

90. Ghalamfarsa G, Kazemi MH, Raoofi Mohseni S, Masjedi A, Hojjat-Farsangi M, Azizi G, Yousefi M, Jadidi-Niaragh F. CD73 as a potential opportunity for cancer immunotherapy. Expert Opin Ther Targets. 2019;23(2):127-42.

91. Takenaka MC, Gabriely G, Rothhammer V, Mascanfroni ID, Wheeler MA, Chao CC, Gutierrez-Vazquez C, Kenison J, Tjon EC, Barroso A, et al. Control of tumor-associated macrophages and T cells in glioblastoma via AHR and CD39. Nat Neurosci. 2019;22(5):729-40.

92. Chen S, Liu H, Su N, Zhang G, Wang L. Myeloid-derived suppressor cells promote age-related increase of lung cancer growth via B7-H1. Exp Gerontol. 2015;61:84-91.

93. Wang T, Chu Z, Lin H, Jiang J, Zhou X, Liang X. Galectin-3 contributes to cisplatin-induced myeloid derived suppressor cells (MDSCs) recruitment in Lewis lung cancer-bearing mice. Mol Biol Rep. 2014;41(6):4069-76.

94. Shvedova AA, Tkach AV, Kisin ER, Khaliullin T, Stanley S, Gutkin DW, Star A, Chen Y, Shurin GV, Kagan VE, et al. Carbon nanotubes enhance metastatic growth of lung carcinoma via up-regulation of myeloid-derived suppressor cells. Small. 2013;9(9-10):1691-5.

95. Shvedova AA, Kisin ER, Yanamala N, Tkach AV, Gutkin DW, Star A, Shurin GV, Kagan VE, Shurin MR. MDSC and TGFbeta are required for facilitation of tumor growth in the lungs of mice exposed to carbon nanotubes. Cancer Res. 2015;75(8):1615-23.

96. Dajon M, Iribarren K, Petitprez F, Marmier S, Lupo A, Gillard M, Ouakrim H, Victor N, Vincenzo DB, Joubert PE, et al. Toll like receptor 7 expressed by malignant cells promotes tumor progression and metastasis through the recruitment of myeloid derived suppressor cells. Oncoimmunology. 2019; 8(1):e1505174

97. Zhang S, Ma X, Zhu C, Liu L, Wang G, Yuan X. The role of myeloid-derived suppressor cells in patients with solid tumors: a meta-analysis. PLoS One. 2016;11(10):e0164514.

98. Iclozan C, Antonia S, Chiappori A, Chen DT, Gabrilovich D. Therapeutic regulation of myeloid-derived suppressor cells and immune response to cancer vaccine in patients with extensive stage small cell lung cancer Cancer Immunol Immunother. 2013;62(5):909-18.

99. Feng PH, Chen KY, Huang YC, Luo CS, Wu SM, Chen TT, Lee CN, Yeh CT, Chuang $\mathrm{HC}$, Han CL, et al. Bevacizumab reduces S100A9-positive MDSCs linked to intracranial control in patients with EGFR-mutant lung adenocarcinoma. J Thorac Oncol. 2018;13(7):958-67.

100. Hoeppner LH, Wang Y, Sharma A, Javeed N, Van Keulen VP, Wang E, Yang P, Roden AC, Peikert T, Molina JR, et al. Dopamine D2 receptor agonists inhibit lung cancer progression by reducing angiogenesis and tumor infiltrating myeloid derived suppressor cells. Mol Oncol. 2015;9(1):270-81.

101. Zheng Y, Xu M, Li X, Jia J, Fan K, Lai G. Cimetidine suppresses lung tumor growth in mice through proapoptosis of myeloid-derived suppressor cells. Mol Immunol. 2013;54(1):74-83.

102. Sawant A, Schafer CC, Jin TH, Zmijewski J, Tse HM, Roth J, Sun Z, Siegal GP, Thannickal VJ, Grant SC, et al. Enhancement of antitumor immunity in lung cancer by targeting myeloid-derived suppressor cell pathways. Cancer Res. 2013;73(22):6609-20.

103. Li A, Barsoumian HB, Schoenhals JE, Cushman TR, Caetano MS, Wang X, Valdecanas DR, Niknam S, Younes Al, Li G, et al. Indoleamine 2,3dioxygenase 1 inhibition targets anti-PD1-resistant lung tumors by blocking myeloid-derived suppressor cells. Cancer Lett. 2018;431:54-63.

104. Orillion A, Hashimoto A, Damayanti N, Shen L, Adelaiye-Ogala R, Arisa S, Chintala S, Ordentlich P, Kao C, Elzey B, et al. Entinostat neutralizes myeloidderived suppressor cells and enhances the antitumor effect of PD-1 inhibition in murine models of lung and renal cell carcinoma. Clin Cancer Res. 2017;23(17):5187-201.

105. Wang Y, Zhang X, Yang L, Xue J, Hu G. Blockade of CCL2 enhances immunotherapeutic effect of anti-PD1 in lung cancer. J Bone Oncol. 2018;11:27-32.

106. Lee JW, Zhang Y, Eoh KJ, Sharma R, Sanmamed MF, Wu J, Choi J, Park HS, Iwasaki A, Kaftan E, et al. The combination of MEK inhibitor with Immunomodulatory antibodies targeting programmed death 1 and programmed death ligand 1 results in prolonged survival in Kras/p53-driven lung cancer. J Thorac Oncol. 2019;14(6):1046-60.

107. Liu W, Wu T-C, Hong D-M, Hu Y, Fan T, Guo W-J, Xu Q. Carnosic acid enhances the anti-lung cancer effect of cisplatin by inhibiting myeloidderived suppressor cells. Chin J Nat Med. 2018;16(12):907-15.

108. Zhao Y, Shao Q, Zhu H, Xu H, Long W, Yu B, Zhou L, Xu H, Wu Y, Su Z. Resveratrol ameliorates Lewis lung carcinoma-bearing mice development, decreases granulocytic myeloid-derived suppressor cell accumulation and impairs its suppressive ability. Cancer Sci. 2018;109(9):2677-86.

109. Liu D, You M, Xu Y, Li F, Zhang D, Li X, Hou Y. Inhibition of curcumin on myeloid-derived suppressor cells is requisite for controlling lung cancer. Int Immunopharmacol. 2016;39:265-72.

110. Gabrilovich DI, Velders MP, Sotomayor EM, Kast WM. Mechanism of immune dysfunction in cancer mediated by immature Gr-1+ myeloid cells. J Immunol. 2001;166(9):5398-406.

111. Kusmartsev S, Su Z, Heiser A, Dannull J, Eruslanov E, Kubler H, Yancey D, Dahm P, Vieweg J. Reversal of myeloid cell-mediated immunosuppression in patients with metastatic renal cell carcinoma. Clin Cancer Res. 2008; 14(24):8270-8.

112. Lee JM, Seo JH, Kim YJ, Kim YS, Ko HJ, Kang CY. The restoration of myeloid-derived suppressor cells as functional antigen-presenting cells by NKT cell help and all-trans-retinoic acid treatment. Int J Cancer. 2012:131(3):741-51.

113. Nefedova Y, Fishman M, Sherman S, Wang X, Beg AA, Gabrilovich DI. Mechanism of all-trans retinoic acid effect on tumor-associated myeloidderived suppressor cells. Cancer Res. 2007;67(22):11021-8.

114. Courau T, Nehar-Belaid D, Florez L, Levacher B, Vazquez T, Brimaud F, Bellier B, Klatzmann D. TGF-beta and VEGF cooperatively control the immunotolerant tumor environment and the efficacy of cancer immunotherapies. JCI Insight. 2016;1 (9):e85974.

115. Lechner MG, Liebertz DJ, Epstein AL. Characterization of cytokine-induced myeloid-derived suppressor cells from normal human peripheral blood mononuclear cells. J Immunol. 2010;185(4):2273-84.

116. Basu S, Nagy JA, Pal S, Vasile E, Eckelhoefer IA, Bliss VS, Manseau EJ, Dasgupta PS, Dvorak HF, Mukhopadhyay D. The neurotransmitter dopamine inhibits angiogenesis induced by vascular permeability factor/vascular endothelial growth factor. Nat Med. 2001;7(5):569-74.

117. Basu S, Sarkar C, Chakroborty D, Nagy J, Mitra RB, Dasqupta PS, Mukhopadhyay D. Ablation of peripheral dopaminergic nerves stimulates malignant tumor growth by inducing vascular permeability factor/vascular endothelial growth factor-mediated angiogenesis. Cancer Res. 2004;64(16):5551-5. 
118. Tilan J, Kitlinska J. Sympathetic neurotransmitters and tumor angiogenesislink between stress and cancer progression. J Oncol. 2010;2010:539706.

119. Tanaka T, Kochi T, Shirakami Y, Mori T, Kurata A, Watanabe N, Moriwaki H, Shimizu M. Cimetidine and clobenpropit attenuate inflammation-associated colorectal carcinogenesis in male ICR mice. Cancers (Basel). 2016;8(2). https://doi.org/10.3390/cancers8020025.

120. Kubecova M, Kolostova K, Pinterova D, Kacprzak G, Bobek V. Cimetidine: an anticancer drug? Eur J Pharm Sci. 2011;42(5):439-44.

121. Gabrilovich DI, Ostrand-Rosenberg S, Bronte V. Coordinated regulation of myeloid cells by tumours. Nat Rev Immunol. 2012;12(4):253-68.

122. Li J, Yu S, Ying J, Shi T, Wang P. Resveratrol prevents ROS-induced apoptosis in high glucose-treated retinal capillary endothelial cells via the activation of AMPK Sirt1/PGC-1alpha pathway. Oxidative Med Cell Longev. 2017;2017:7584691.

123. Bastianetto S, Menard C, Quirion R. Neuroprotective action of resveratrol. Biochim Biophys Acta. 2015;1852(6):1195-201.

124. Zordoky BN, Robertson IM, Dyck JR. Preclinical and clinical evidence for the role of resveratrol in the treatment of cardiovascular diseases. Biochim Biophys Acta. 2015;1852(6):1155-77.

125. Springer M, Moco S. Resveratrol and its human metabolites-effects on metabolic health and obesity. Nutrients. 2019;11(1). https://doi.org/10.3390/ nu11010143.

126. Gwak H, Kim S, Dhanasekaran DN, Song YS. Resveratrol triggers ER stressmediated apoptosis by disrupting $\mathrm{N}$-linked glycosylation of proteins in ovarian cancer cells. Cancer Lett. 2016;371(2):347-53.

127. Buttari B, Profumo E, Segoni L, D'Arcangelo D, Rossi S, Facchiano F, Saso L, Businaro R, Iuliano L, Rigano R. Resveratrol counteracts inflammation in human M1 and M2 macrophages upon challenge with 7-oxo-cholesterol: potential therapeutic implications in atherosclerosis. Oxidative Med Cell Longev. 2014;2014:257543.

128. Singh NP, Hegde VL, Hofseth LJ, Nagarkatti M, Nagarkatti P. Resveratrol (trans-3,5,4'-trihydroxystilbene) ameliorates experimental allergic encephalomyelitis, primarily via induction of apoptosis in T cells involving activation of aryl hydrocarbon receptor and estrogen receptor. Mol Pharmacol. 2007;72(6):1508-21.

129. Lu Y, Miao L, Wang Y, Xu Z, Zhao Y, Shen Y, Xiang G, Huang L. Curcumin micelles remodel tumor microenvironment and enhance vaccine activity in an advanced melanoma model. Mol Ther. 2016;24(2):364-74.

130. Liao C, Yu Z, Guo W, Liu Q, Wu Y, Li Y, Bai L. Prognostic value of circulating inflammatory factors in non-small cell lung cancer: a systematic review and meta-analysis. Cancer Biomark. 2014;14(6):469-81.

131. Shen L, Orillion A, Pili R. Histone deacetylase inhibitors as immunomodulators in cancer therapeutics. Epigenomics. 2016;8(3):415-28.

132. Simanshu DK, Nissley DV, McCormick F. RAS proteins and their regulators in human disease. Cell. 2017;170(1):17-33.

133. Blumenschein GR Jr, Smit EF, Planchard D, Kim DW, Cadranel J, De Pas T, Dunphy F, Udud K, Ahn MJ, Hanna NH, et al. A randomized phase II study of the MEK1/MEK2 inhibitor trametinib (GSK1120212) compared with docetaxel in KRAS-mutant advanced non-small-cell lung cancer (NSCLC)dagger. Ann Oncol. 2015;26(5):894-901.

134. Hainsworth JD, Cebotaru CL, Kanarev V, Ciuleanu TE, Damyanov D, Stella P. Ganchev H, Pover G, Morris C, Tzekova V. A phase II, open-label, randomized study to assess the efficacy and safety of AZD6244 (ARRY-142886) versus pemetrexed in patients with non-small cell lung cancer who have failed one or two prior chemotherapeutic regimens. J Thorac Oncol. 2010;5(10):1630-6.

135. Eksioglu EA, Chen X, Heider KH, Rueter B, McGraw KL, Basiorka AA, Wei M, Burnette $A$, Cheng $P$, Lancet J, et al. Novel therapeutic approach to improve hematopoiesis in low risk MDS by targeting MDSCs with the Fc-engineered CD33 antibody BI 836858. Leukemia. 2017;31(10):2172-80.

136. Nejadmoghaddam MR, Minai-Tehrani A, Ghahremanzadeh R, Mahmoudi M, Dinarvand R, Zarnani AH. Antibody-drug conjugates: possibilities and challenges. Avicenna J Med Biotechnol. 2019;11(1):3-23.

137. Yu B, Liu D. Gemtuzumab ozogamicin and novel antibody-drug conjugates in clinical trials for acute myeloid leukemia. Biomark Res. 2019;7:24.

138. Fultang L, Panetti S, Ng M, Collins P, Graef S, Rizkalla N, Booth S, Lenton R, Noyvert B, Shannon-Lowe C, et al. MDSC targeting with Gemtuzumab ozogamicin restores $\mathrm{T}$ cell immunity and immunotherapy against cancers. EBioMedicine. 2019:47:235-46.

\section{Publisher's Note}

Springer Nature remains neutral with regard to jurisdictional claims in published maps and institutional affiliations.

Ready to submit your research? Choose BMC and benefit from:

- fast, convenient online submission

- thorough peer review by experienced researchers in your field

- rapid publication on acceptance

- support for research data, including large and complex data types

- gold Open Access which fosters wider collaboration and increased citations

- maximum visibility for your research: over $100 \mathrm{M}$ website views per year

At BMC, research is always in progress.

Learn more biomedcentral.com/submissions 